\title{
EN LA BÚSQUEDA DE UN ROSTRO PARA EL BOCETO DEL LEGISLADOR: LA CONDICIÓN DE "HEREDERO" ESPECIALMENTE PROTEGIDO (LEGITIMARIO ASISTENCIAL) EN LA INTERPRETACIÓN DEL TRIBUNAL SUPREMO DE CUBA*
}

THE QUEST FOR A FACE OF A LAW DRAFT: THE STATUS OF SPECIALLY PROTECTED “INHERITOR” (RELIEF HEIR) UNDER THE

interpretation of THE Cuba Supreme CourT

A LA RECHERCHE D'UN VISAGE POUR UNE ESQUISSE DU LÉGISLATEUR: LE STATUT DE “HÉRITIER” SPÉCIALEMENT PROTÉGÉ (LEGITIMARIO D’ASSISTANCE) DANS L'INTERPRÉTATION DE LA COUR SUPRÊME DE LA Cuba

Leonardo B. Pérez Gallardo*

\begin{abstract}
RESUMEN
El artículo analiza el alcance de los herederos especialmente protegidos, los nuevos legitimarios asistenciales con los que dotó al Derecho de Sucesiones el Código Civil cubano. Las circunstancias que cualifican la condición de legitimario asistencial, son por regla general transitorias, como lo es la minoridad o como lo pueden ser ciertas discapacidades o la situación de dependencia o vulnerabilidad económica. Incluso personas con discapacidad intelectual severa o profunda, pueden depender económicamente de una persona y en un momento dado, cesar esa dependencia por disponer de un patrimonio que en el orden económico le permita tener cubiertas todas sus necesidades.
\end{abstract}

PALABRAS CLAVE: Legitimario asistencial - Herederos especialmente protegidos - Legítima asistencial - Derecho sucesorio cubano

ABSTRACT

This article discusses the extension of the "specially protected inheritors": the newly created relief heirs that the Cuban Civil Code established as a part of the inheritance law. The circumstances that allow to qualify a person as a relief heir, are usually transitory, e.g. minority, special abilities and/or economic dependency or vulnerability. Even people with special abilities may depend financially on other person, and in any given moment, such dependence may be ended by having enough assets to cover all of his/her expenses and necessities.

KEY WORDS: Relief heir - Specially protected inheritors - Relief inheritance - Cuban Inheritance Law

\footnotetext{
*El artículo fue aprobado para su publicación el 15 de abril de 2013.

** Abogado. Licenciado en Derecho de la Universidad de La Habana, Cuba. Máster en Derecho Privado por la Universidad de Valencia, España. Doctor en Ciencias Jurídicas por la Universidad de La Habana. Profesor Titular de Derecho Civil y Derecho Notarial, Facultad de Derecho, Universidad de La Habana. Notario. Correo electrónico: lbpgallardo@gmail.com.
} 


\section{RÉSUMÉ}

L'article traite de la portée des héritiers spécialement protégés, la nouvelle protection des héritiers dans le droit des successions du Code civil cubain. Les circonstances qui qualifient la situation de protection d'héritier, étaient généralement transitoires, comme minorité ou certains handicaps ou l'état de dépendance ou de vulnérabilité économique. Même les personnes ayant une déficience intellectuelle sévère ou profonde peut être financièrement dépendant d'une personne. Mais la dependence peut cesser, au le moment d'avoir des actifs dans l'ordre économique qui permettent couvrir tous ses besoins.

MoTS CLÉS: Protection de héritier - Les héritiers spécialement protégés - Légitime protegéDroit des successions cubaine

\section{LOS “HEREDEROS” ESPECIALMENTE PROTEGIDOS: \\ Su DEVENIR EN LOS DISTINTOS ANTEPROYECTOS DEL \\ Código Civil de 1987. Primeras Pinceladas}

Mientras me decido a escribir estas páginas, veinticinco años después de la promulgación del Código Civil, paso revista al devenir en este cuarto de siglo de una institución forjada, como he dicho otras veces, a fuerza de cincel y martillo jurisprudencial, con los vaivenes que la interpretación judicial suele provocar en las instituciones jurídicas, de la cual no escapa la presente.

Cuando el 16 de julio de 1987 fue aprobado por la Asamblea Nacional el Código Civil cubano, se daba fin al itinerario por el que había atravesado la espina dorsal de nuestro Derecho sucesorio, figura en derredor de la cual se suponía sería construido el edificio en que se sostendría una buena parte del resto de las instituciones sucesorias, si los "arquitectos" que en su momento diseñaron ese edificio legal, y los "ingenieros civiles" que luego fueron sus ejecutores, lo hubieren hecho con sentido de la simetría, la topografía, la geometría del espacio y con una base de cálculo que permitiera una cimentación para actuar sobre un terreno firme y sobre todo antisísmico. Hoy, veinticinco años después, estoy lleno de dudas, en una búsqueda continua de la ratio legis, y desde la academia he tenido que atravesar por angosturas, superar antinomias, proponer soluciones para colmar lagunas u ofrecer otras que desde la hermenéutica jurídica, esencialmente correctora, dé sentido, lógica y sobre todo aplicación a un Derecho en que lo justo natural se imponga a la exégesis de la norma. Muchas veces la fatiga intelectual de este continuo ejercicio me obliga a tomar cierto respiro, inhalo oxígeno y sigo en pie, pero cuando creo que he avanzado en este devenir reconstructivo, me percato que el camino trillado es escaso si se toma en cuenta que aún el rostro del boceto legislativo de los aparentemente archiconocidos "herederos" especialmente protegidos no se deja aún ver en sus más diversos perfiles, a pesar de todo lo transitado, de todo lo que en estos años he tenido que labrar, bien a través de lo que he dejado escrito ${ }^{1}$ o de

${ }^{1}$ Pérez Gallardo, Leonardo B. (1999). "Los herederos especialmente protegidos, la nueva visión de los legitimarios en el Código Civil cubano: Algunas interrogantes al respecto”. En: Temas de Derecho Sucesorio 
EN LA BÚSQUEDA DE UN ROSTRO PARA EL BOCETO DEL LEGISLADOR: LA CONDICIÓN DE “HEREDERO” ESPECIAMENTE PROTEGIDO (LEGITIMARIO ASISTENCIAL) EN LA INTERPRETACIÓN DEL TRIBUNAL

lo que han hecho algunos de mis discípulos en estos tiempos de intenso bregar ${ }^{2} \mathrm{o}$ valiosos profesores de otras universidades del país ${ }^{3}$.

Un fugaz recorrido por los anteproyectos y el proyecto, del luego devenido Código Civil, pudiera ofrecernos algunas pistas interesantes en esta labor hermenéutica. De un estudio sistemático de los anteproyectos podemos llegar a ciertas conclusiones: para el legislador siempre estuvo claro la permanencia de unos herederos forzosos, con una nueva visión, con un estilo distinto ${ }^{4}$, tomado de modelos de Europa del Este , pero que en esencia respondía a un límite a la libertad de testar,

Cubano, La Habana: Félix Varela, pp. 15-59; Pérez Gallardo, Leonardo B. y Cobas Cobiella, María Elena (1999). "A una década de la promulgación el Código Civil cubano: reflexiones sobre algunos aciertos y desaciertos de su Libro Cuarto". En: Temas de Derecho Sucesorio Cubano, La Habana: Félix Varela, pp. 61-221; Pérez Gallardo, Leonardo B. (2000). "Naturaleza intuitu personae de los derechos deferidos a favor de los padres con especial protección (y no herederos especialmente protegidos) en el primer llamado sucesorio. (Comentarios a la Sentencia No 46 de la Sala de lo Civil y lo Administrativo del Tribunal Supremo de 29 de enero de 1999)". Revista Jurídica, Ministerio de Justicia, La Habana, No 1, enero, pp. 6-25; Pérez Gallardo, Leonardo B. (2004b). "Los herederos especialmente protegidos. La legítima. Defensa de su intangibilidad cualitativa y cuantitativa”. En: Derecho de Sucesiones, T. II, Pérez Gallardo, Leonardo B. (Coord.), La Habana: Félix Varela, pp. 200-310; Pérez Gallardo, Leonardo B. (2010a). "Algunos criterios jurisprudenciales en sede sucesoria de la Sala de lo Civil y de lo Administrativo del Tribunal Supremo. Derroteros del último lustro (2000-2004)". En: Estudios de Jurisprudencia sucesoria, Managua: Bitecsa, pp. 49-152; Pérez Gallardo, Leonardo B. (2009). "Declaración post mortem de la inoficiosidad de la donación y la protección de la legítima. (A propósito de la Sentencia No 58 de 23 de marzo de 2009 de la Sala de lo Civil y de lo Administrativo del Tribunal Supremo)". Revista Cubana de Derecho, La Habana, No 34, julio-diciembre, pp. 141-159; Pérez Gallardo, Leonardo B. (2010b). "El Derecho de Sucesiones a la luz de la interpretación de la Sala de lo Civil y de lo Administrativo del Tribunal Supremo en el cuatrienio 2005-2008”. En: Estudios de Jurisprudencia sucesoria, Managua: Bitecsa, pp. 153-270; PÉreZ Gallardo, Leonardo B. (2011a). "Legítima y discapacidad. Una relectura de los requisitos exigidos ex lege para el beneficio de la especial protección o cualidad de legitimario asistencial". Revista Norte Notarial, del Colegio de Notarios de La Libertad, Trujillo, año I, No 1, pp. 23-44; Pérez Gallardo, Leonardo B. (2011b). "Cumplimiento de los requisitos de la especial protección (legitimario asistencial) a la muerte del testador: La situación del estudiante universitario. Comentarios a la Sentencia No 218 de 31 de mayo de 2011 de la Sala de lo Civil y de lo Administrativo del Tribunal Supremo". En: Boletín de la Organización Nacional de Bufetes Colectivos, La Habana, No 42, junio-diciembre, pp. 5-17; Pérez Gallardo, Leonardo B. (inédito). “¿Cómo entender la dependencia económica del causante, a los fines de reclamar la legítima, en el supuesto del hijo judicialmente incapacitado, internado en centro asistencial? (A propósito de la Sentencia No 532 de 29 de diciembre de 2011 de la Sala de lo Civil y de lo Administrativo del Tribunal Supremo)".

${ }^{2}$ Vid. la reciente tesis de doctorado defendida por Alfaro Guillén, Yanet (2012). El régimen jurídico de la preterición en Cuba. Facultad de Derecho, Universidad de La Habana, bajo mi dirección.

${ }^{3}$ Fernández Martell, José Karel y Panadero de la Cruz, Ediltrudis (2011). "Las donaciones colacionables: el enigma de una institución jurídica. Incidencias sustantivas para el Derecho positivo cubano”. Revista del Centro de Investigaciones Sociojurídicas de la Universidad de Caldas, Manizales, Vol. 8, No 1, enero-junio, pp. 13-44.

${ }^{4}$ Marcado esencialmente por la función social que tiene la legítima, catalogada como asistencial, precisamente en razón de la protección que despliega hacia un cierto sector de la población, en esencia, personas dependientes económicamente o con discapacidad.

${ }^{5}$ Como exponen Czachorski, Witold y Stelmachowski, Andrezj. "Evolución del Derecho Civil en los países socialistas". Disponible en: <http://biblio.juridicas.unam. mx/libros/2/889/3.pdf> [consulta: 2 agosto 2012], pp. 57-58, en Rusia y la ex Checoslovaquia eran llamadas a la sucesión del de cuius las personas que hubieran estado en dependencia económica con éste, por lo menos, un año antes de su muerte. 
si bien por excepción, pero límite al fin. Nunca se pensó en suprimir esta cortapisa a la libertad de testar del individuo, se pasó de la regulación de unos herederos apegados en su nomen y en su contenido a los previstos por el legislador español, a otros en lo que mutaba su esencia más asistencial que parental, constituyendo ambos igual freno a la libertad testamentaria, pero se buscaba en este nuevo ensayo normativo la protección de ciertos parientes en razón de requerimientos a modo de conditio iuris que se iban agregando ${ }^{6}$.

El actual Código Civil ruso mantiene esta dirección. En efecto, el artículo 1148 regula la sucesión por discapacitados dependientes del testador.

A su tenor: "1. Los ciudadanos que se encuentran comprendidos entre los herederos legales, especificados en los artículos 1143-1145 del presente Código que se encuentran discapacitados en la fecha de apertura de la sucesión, pero que no están incluidos en la categoría de herederos llamados a la herencia, deben heredar, por ministerio de la ley, de conjunto y a partes iguales con los herederos de esa categoría, si eran dependientes del testador, al menos un año antes de su muerte, sin importar si residian o no con el testador".

"2. Los herederos legales no deben ser incluidos en el círculo de herederos especificados en los artículos 1142-1145 del Código, salvo que fueren discapacitados en el momento de apertura de la sucesión, y que fueren dependientes del testador al menos por un año antes de su muerte, habiendo residido con él. Si existen otros herederos legales deben heredar a partes iguales con los herederos de la categoría llamada a la herencia".

"3. Si no hay otros herederos legales, los discapacitados dependientes del testador deben heredar por derecho propio como herederos de la octava categoría".

${ }^{6}$ Paradójicamente, casi un cuarto de siglo después de que el legislador cubano sancionara el Código Civil de 1987, la polémica en la doctrina española sobre la necesidad de reformas en materia sucesoria, y en concreto en sede de legítimas resulta bien enconada. Autores como Calatayud Sierra, Adolfo (1995). "Consideraciones acerca de la libertad de testar". En: Academia Sevillana del Notariado, T. IX, Edersa, pp. 243-263, en su sentida condición de notario, propone una abrogación absoluta de las legítimas (tanto material como formal) y de las reservas, y en sustitución de las primeras, el establecimiento del derecho de alimentos a cargo de la herencia y a favor de los descendientes del causante. Asimismo, DE la Esperanza Rodríguez, Pablo (2002). "Perspectiva de la legítima. Notas para una posible revisión". En: Libro Homenaje a Ildefonso Sánchez Mera, Vol. I, Consejo General del Notariado, pp. 1097-1116, con similar parecer, siguiendo los derroteros de CALATAYUD SiERRA, aboga por la supresión de las legítimas y en su lugar "un sistema de alimentos respecto de los hijos o nietos que, al fallecimiento del testador, estén en situación de pedirlos". Similar posición la de Magariños Blanco, Victorio (2005). "La libertad de testar". Revista de Derecho Privado, Nos. 9-10, septiembre-octubre. Disponible en: <http://vlex.com/ vid/libertad-testar-289842> [consulta: 7 agosto 2012], p. 25, quien aboga por una libertad de testar, en tanto que las legítimas, a su juicio, constituyen un escollo en una importante etapa de la vida como es la vejez, dado que se le impide a la persona "subvenir a las atenciones que su vida reclama, sirviendo de substrato económico para que (...) pueda desarrollarse plena y dignamente hasta el momento mismo de su muerte", mientras que "la libertad de testar es hoy el instrumento más idóneo para ajustar el patrimonio a la finalidad que debe cumplir, que es atender a las necesidades del que lo ha creado". Gomá Lanzón, Ignacio (2005). "Atribuciones legales (legítimas, los derechos del cónyuge viudo y de las parejas, reservas). Parte segunda. Los derechos del cónyuge viudo”. En: Instituciones de Derecho Privado, Delgado de Miguel, Juan Francisco (Coord. Gral.), Garrido Melero, Martín (Coord.), T. V: Sucesiones, Vol.: $3^{\circ}$ Las atribuciones legales, Madrid: Thomson-Civitas, p. 934, con un tono algo más moderado, pero en esencia, con los mismos derroteros, expone que "el progresivo desarrollo del individualismo y de la libertad personal parecen exigir la reducción o eliminación de las legítimas en aquellas legislaciones en las que su existencia supone una verdadera traba para la libertad de testar que permita al causante adaptar su sucesión a las necesidades familiares". Asimismo, GarCía SÁncheZ, José Aristónico (2009). "El Notario del siglo XXI". Revista del Colegio Notarial de Madrid, No 24, marzo-abril, pp. 78-80, aprovecha la ocasión para rematar una idea que en España ha fecundado en los despachos notariales, por ser precisamente los notarios, como expresa GOMÁ LANZÓN, quienes tienen un "conocimiento directo del 
EN LA BÚSQUEDA DE UN ROSTRO PARA EL BOCETO DEL LEGISLADOR: LA CONDICIÓN DE “HEREDERO” ESPECIAMENTE PROTEGIDO (LEGITIMARIO ASISTENCIAL) EN LA INTERPRETACIÓN DEL TRIBUNAL

En la exposición de motivos del entonces anteproyecto de Código Civil cubano, de 27 de agosto de 1987, se justifica la clasificación de los herederos forzosos, distinguiéndose de los herederos legítimos y de los testamentarios, pero ya en la ocasión se hace un giro respecto de los que el Código Civil español, a la sazón aún vigente en esa fecha incluía como tales ${ }^{7}$, de modo que se reducen con exclusivi-

pensamiento de los testadores". De modo que acusa a las legítimas de ser una institución anacrónica "cuya rigidez los avispados encuentran mil escapes para burlar y que, en cambio, para los ciudadanos de a pie que son los más, se convierten en obstáculos insuperables que les impiden conseguir el mejor favor familiae". No obstante, sus palabras finales se dirigen a la reorientación de las legítimas a los efectos de "asegurar la responsabilidad del testador respecto de los que lo necesiten y sólo en la cuantía en que lo necesiten”. Otros como Delgado Echevarría, Jesús (2009). “¿Qué reformas cabe esperar del Derecho de sucesiones del Código Civil? (Un ejercicio de prospectiva)”. Disponible en: <http://www.codigo-civil. info/nulidad/lodel/docannexe.php?id=742> [consulta: 6 agosto 2012], proponen, entre otros temas, que en futuras reformas al Derecho de sucesiones español se prevean "reglas según las cuales los allegados a quienes la muerte del causante ha privado de recursos para la vida hayan de recibir necesariamente alguna cantidad a cargo de la herencia”.

Por su parte, VAQUer Aloy, Antoni (2007). "Reflexiones sobre una eventual reforma a la legítima”. InDret, 3/2007. Disponible en: <http://www.indret.com/pdf/457_es.pdf> [consulta: 6 agosto 2012], desecha la posibilidad de admitir en España la sustitución de las legítimas por un derecho de alimentos, de modo que es partidario de un cambio en la función social de las legítimas, en todo caso habría que reducir el número de sus beneficiarios. En este sentido "las razones de simplificación y previsibilidad del sistema legitimario llevarían, una vez desestimada la opción de vincular legítima con derecho de alimentos de un modo más íntimo, a establecer una categoría fija de legitimarios. En ella (...) no entrarían los ascendientes. La legítima quedaría restringida, pues, a los hijos - y a su descendencia por derecho de representación-y al cónyuge. Al cónyuge en todo caso, a los hijos sólo en el supuesto que deba manifestarse con vigor el principio de solidaridad intergeneracional. De entrada, sin duda deberían serlo los hijos menores de edad y los incapacitados". En el caso de los menores de edad su propuesta se reduce a los que tengan menos de 25 años, en tanto que en sede de incapacitados judicialmente "la propuesta sería ampliar la categoría de legitimarios a quienes tienen reconocido algún grado de discapacidad por las autoridades administrativas competentes".

Con una posición más escéptica y ambivalente se pronuncia Parra LuCÁn, María de los Ángeles (2009). "Legítimas, libertad de testar y transmisión de un patrimonio". AFDUDC, No 13. Disponible en: <http://ruc.udc.es/dspace/bitstream/2183/7529/1/AD_13_art_24.pdf> [consulta: 6 agosto 2012]. Esta autora si bien reconoce la necesidad de una reforma en materia de legítimas, no comparte del todo la opinión de una revisión a fondo de la función de las legítimas, de modo que se oriente el timonel hacia una legítima de corte asistencial. A su juicio, "a las opiniones de fondo enfrentadas en este debate debe añadirse (...), que la sustitución del sistema de legítimas por un derecho de alimentos ofrece para su implantación general en el Derecho español algunas dificultades. A los problemas de determinación de si el momento relevante para apreciar la situación de necesidad es exclusivamente el de la muerte del causante (lo que puede resultar injusto) se añaden otros, como el excesivo choque con la tradición de las legítimas por cuotas, lo que indudablemente daría lugar a costes adicionales de transacción (consultas jurídicas, pleitos).

"Además, quienes defienden este derecho de alimentos para los descendientes necesitados como alternativa a su derecho a la subsistencia no son totalmente coherentes con los derechos que reconocen al cónyuge o a la pareja de hecho, que no se hacen depender de situación de necesidad alguna, dando por supuesto que la mejor situación del viudo o la pareja así lo exige, con independencia de su nivel y situación económica tras el fallecimiento", en la cual le asiste razón su crítica.

${ }^{7}$ En el artículo 807 se regulaba quiénes se consideraban herederos forzosos, a saber:

"10 Los hijos y descendientes respecto de sus padres y ascendientes.

$2^{\circ} \mathrm{A}$ falta de los anteriores, los padres y ascendientes respecto de sus hijos y descendientes.

$3^{\circ}$ El viudo o viuda, en la forma y medida que establecen los artículos 834, 835, 836 y 837”.

Revista de Derecho · Escuela de Postgrado No 3, julio 2013

Páginas $51-94$ 
dad únicamente a los descendientes, ya sean consanguíneos o por adopción ${ }^{8}$, en consecuencia, quedarían excluidos los ascendientes y el cónyuge. Colígese de esta posición que en la mens legislatoris, desde sus albores codificadores, el principio de ensanchamiento de la libertad de testar fue evidente, al reducirse de manera drástica el círculo de sujetos incluidos bajo la condición de herederos forzosos, denominación hispana que se mantiene en estos primeros bocetos normativos. Anoto que serían a juicio del legislador herederos forzosos los descendientes, sin más requerimientos legales, suficiente con que se probara la condición de descendientes respecto del causante de la sucesión, ya fuere por sangre o por adopción.

Empero, al parecer resultan contradictorias las fechas de las fuentes que he consultado, pues a pesar de que en esta exposición a la que he hecho referencia, de las poquísimas con las que hoy en día se cuentan del íter legislativo del Código, de 27 de agosto de 1979, en la versión del anteproyecto de 6 de febrero de ese año, el círculo de sujetos incluido bajo la denominación de herederos forzosos es más amplio, pues incluye también al cónyuge, no así a los ascendientes con alcance general, y se introduce por vez primera a los que luego devendrían bajo la denominación de especialmente protegidos. En efecto, en el artículo 468.2 de esta versión del anteproyecto se introducen los requerimientos de incapacidad para trabajar y permanencia bajo manutención total del fallecido durante un término no inferior a un año antes de su muerte (expresión tomada del Código Civil de la RSFSR, que así lo regulaba), de los menores de edad y de las personas incapacitadas para el trabajo 9 . Fórmula ambigua, pues no acotaba el vínculo parental que debían tener los unos con los otros respecto del causante de la sucesión, como luego se hizo. Si esos menores eran hijos o descendientes del causante, resultaba entonces tautológico, pues al reconocer el artículo 468.1 que todo descendiente consanguíneo o adoptado era heredero forzoso, innecesario era incluir a los descendientes menores de edad con tales requerimientos pues quedarían incluidos en el inciso $1^{\circ}$. Vale acotar la manifiesta intención del legislador de proteger a personas dependientes económicamente respecto del causante y sobre todo a las personas incapacitadas, esencialmente mayores de edad, en tanto los ascendientes no que-

\footnotetext{
${ }^{8}$ Intenta el legislador estar a tono con la fórmula empleada por el ya promulgado en 1975, Código de Familia que en su artículo 99 establecía que el parentesco por adopción es igual al existente entre padres e hijos. He de advertir que la adopción regulada por el Código de Familia, luego fue modificada por el Decreto-Ley No 76/1984, pero no en cuanto a este principio enarbolado desde su primigenia aprobación por el Código, en 1975.

${ }^{9}$ El Derecho de la antigua Unión Soviética establecía bajo la categoría de herederos indispensables con derecho a una "parte hereditaria obligatoria", a los hijos del causante, incluidos los adoptivos, el cónyuge, los padres (ya sean consanguíneos o por adopción) que dependieran económicamente de aquél o estuvieren en situación de incapacidad para trabajar, cuota que ascendía a dos tercios de los bienes, que correspondieran a cada uno de ellos al heredar por ley. Incluso en los casos en que el testador privare del derecho de heredar a los sucesores indispensables, éstos tenían derecho sobre la parte obligatoria de la herencia. Si tales derechos eran conculcados, se reconocía entonces inválido el testamento. Vid. AA.VV. (1985). Derecho Civil soviético. T. II (traducido del ruso), Moscú: Yneshtorgizdat, pp. 386-387.
} 
EN LA BÚSQUEDA DE UN ROSTRO PARA EL BOCETO DEL LEGISLADOR: LA CONDICIÓN DE “HEREDERO”

daban comprendidos en la órbita de aplicación del artículo 468 del anteproyecto. La sucesión forzosa quedaba regulada en los artículos 473 al 478, ambos inclusive. Los herederos forzosos serían concurrentes sin prelación entre sí, con derecho a dos tercios del caudal hereditario, y con acrecimiento entre ellos. El cónyuge se consideró un heredero forzoso más, con derecho a una participación en igual concepto que la del resto de los herederos forzosos y sin perjuicio de su participación en la comunidad matrimonial de bienes (artículo 474 in fine) e incluso se llegó a establecer que "Si el causante no hubiera dispuesto del tercio de su herencia que es de libre disposición, los herederos forzosos dividen en partes iguales la totalidad del haber líquido hereditario", es decir, un efecto expansivo extraordinario, ex lege, a favor de los herederos forzosos, sin necesidad de abrir la sucesión intestada para atribuir ese tercio sobre el que el testador nada expresamente había dispuesto.

En una de las versiones del anteproyecto de Código Civil, redactada en septiembre de 1985 por la comisión que presidió Blas RocA, este boceto legislativo deja extender algunos que otros trazos de la figura. La denominación heredero forzoso desaparece y en su lugar se le atribuye la de herederos legales especialmente protegidos, que salvo el adjetivo "legales", utilizado en el nomen iuris de la figura, tiene exactamente la misma redacción que el actual artículo 493 del vigente Código Civil. Queda claro en este anteproyecto no sólo la órbita subjetiva de aplicación de ésta, sino también sus requerimientos de naturaleza objetiva, tal cual hoy se conciben, a saber: yuxtapuestos con el vínculo parental o conyugal que al efecto se exige. Precepto después reproducido en el artículo 501 del proyecto de mayo de 1986, ahora sí, con el único cambio de suprimir el adjetivo "legales", lo cual aún me resulta desconocido por carencia de borradores, o actas de discusión entre los miembros de la comisión codificadora, perdida la información, como tanta otra tan valiosa para la hermenéutica del Código Civil, en la noche eterna de los tiempos. De modo que, sólo retazos tiene a su favor cualquier investigador, amén de alguna que otra información obtenida en conversaciones con los codificadores sobrevivientes.

\section{La figura en el Código Civil de 1987: UN MERO BOCETO DEL LEGISLADOR}

El rostro que buscamos quedó meramente esbozado por un legislador que lo cristalizó en apenas cuatro artículos del Libro dedicado al Derecho de Sucesiones, a lo cual se le suman otros esparcidos en el propio Código como el 530 en sede de colación y los artículos 514.2 y 516, relativos a la sucesión de los padres son especial protección como concurrentes en el primer llamado sucesorio. El Código Civil de 1987 se caracterizó por el laconismo exacerbado de sus preceptos, el empleo de conceptos válvulas destinados a ser aplicados por jueces con una fértil "imaginación", a partir del empleo de los distintos métodos hermenéuticos, con los cuales develar el secreto de esos trazos de pintura abstracta de finales del siglo XX, cuya 
interpretación depende del perfil desde el cual se le mire. El legislador no completó la obra, la dejó en manos de los jueces y de los demás aplicadores del Derecho, en la que la doctrina científica ha desempeñado un rol significativo, tenida en cuenta incluso por el juzgador en algunas de sus sentencias relativas precisamente a este tema en las que se apoya en su argumentación jurídica ${ }^{10}$.

Cabe entonces sustentar que los denominados "herederos" especialmente protegidos nacen a la palestra legal, como sustitutivos de los "herederos" forzosos reconocidos en el artículo 807 del Código Civil español, a la postre, abrogado. Tienden a proteger a personas con dependencia económica, vulnerables económicamente, con ciertas discapacidades que le llevan a una falta de aptitud para trabajar, dentro de un círculo parental y conyugal que no se distancia en nada del enunciado en el mencionado artículo 807, pero al introducir los dos requerimientos a modo de conditio iuris, que más de una vez ha provocado un verdadero quebradero de cabeza, a saber: la dependencia económica del causante y la falta de aptitud para trabajar, deja en manos de los operadores del Derecho su exégesis (esencialmente de los jueces), quienes tienen que seguir completando trazos, para culminar la obra inconclusa del legislador. De esta manera la figura de los "herederos" especialmente protegidos, no es únicamente de contornos o perfiles legales, sino también de constitución jurisprudencial, con el sentido que suele darle la academia cubana a este término, que no supone recta vía, lo que en esencia es la jurisprudencia ${ }^{11}$. No se es especialmente protegido sólo por determinación legal, sino esencialmente por determinación judicial e incluso notarial. Las bases de esta determinación las da la ley, pero su contenido se colma por la labor de los intérpretes. Los requerimientos de la figura, a modo de conditio iuris han sido perfilados por los jueces en estos casi cinco lustros de vigencia del Código Civil, con el aditamento, nada pueril, de la doctrina científica, nacida en esencia desde la cátedra universitaria que ha puesto lienzo y pincel en una obra pictórica de hondo calado humano.

\subsection{El "heredero" especialmente protegido: ¿Un legitimario asistencial?}

Es cierto, el legislador del Código Civil de 1987 en modo alguno emplea el término legítima para hacer referencia a la parte del patrimonio hereditario destinada a determinados sujetos, calificados como legitimarios. Pero denomí-

\footnotetext{
${ }^{10}$ Vid. entre otras, en la interpretación del artículo 493 del Código Civil, Sentencia No 75, de 31 de marzo de 2009, segundo Considerando, Sala de lo Civil y de lo Administrativo del Tribunal Supremo (ponente Díaz Tenreiro) y en sede de preterición (artículo 495 del Código Civil) la Sentencia No 317, de 12 de mayo de 2005, primer Considerando, Sala de lo Civil y de lo Administrativo, Tribunal Supremo (ponente González García), Sentencia No 828, de 23 de noviembre de 2004, único Considerando y Sentencia No 768, de 30 de noviembre de 2005, Único Considerando, ambas de la Sala de lo Civil y de lo Administrativo, Tribunal Supremo (ponente Díaz Tenreiro).

${ }^{11}$ Rectius, interpretación jurisprudencial.
} 
EN LA BÚSQUEDA DE UN ROSTRO PARA EL BOCETO DEL LEGISLADOR: LA CONDICIÓN DE “HEREDERO” ESPECIAMENTE PROTEGIDO (LEGITIMARIO ASISTENCIAL) EN LA INTERPRETACIÓN DEL TRIBUNAL

nese legalmente o no legitimarios, creo haber demostrado en estos años que esa parte inamovible, tutelada por normas de ius cogens, de necesaria atribución por el testador, ya sea a título inter vivos o mortis causa (colígese del artículo 494 del propio Código Civil) y no necesariamente por herencia, es lo que el legislador español denominó legítima (vid. artículo 806), a tono con otros ordenamientos jurídicos, contemporáneos o no del legislador español, y con el propio legislador cubano un siglo después, y que situó en el mismo orden que el anterior, sólo con la posición más aparente que real, de no atribuirle una denominación propia desde el Derecho vigente. Pero ¿̇es el nomen de una institución el que le atribuye el ser a la institución? ¿No sería, en todo caso, la naturaleza de las cosas de la que hay que derivar su propia razón de existencia para una adecuada ubicación en la red de instituciones jurídicas? ¿No es el legislador quien le impone al testador su reconocimiento en el propio acto testamentario, sin importar la causa de atribución de esa parte del caudal patrimonial? ¿No se protege esa cuota aun por normas reguladoras de las donaciones, que las califica de inoficiosas cuando la liberalidad se excede de lo que pueda darse o atribuirse por testamento, cualquiera haya sido la fecha de otorgamiento de la donación, incluso en una fecha en la que aún no se tenían especialmente protegidos, si a la muerte del otrora donante sobrevienen especialmente protegidos? Todas las interrogantes apuntan a que, sin dudas los denominados "herederos" especialmente protegidos, son tan legitimarios, como en su día lo fueron los "herederos" forzosos. Unos y otros son tan necesarios, tan forzosos, tan impuestos, con la peculiaridad que la legítima que se atiende por el legislador del Código Civil cubano tiene corte asistencial, o sea, se trata de un sujeto en que los vínculos de sangre y conyugales importan, pero no son suficientes per se para arroparse de la condición de legitimarios.

El legislador patrio, en fecha tan temprana, como 1987, dio el salto cualitativo que hoy 25 años después se reclama por la doctrina científica, incluso en reuniones o congresos internacionales ${ }^{12}$ : La necesidad de reformar el sistema legitimario en Iberoamérica, en pos de una legítima de nuevo corte, con una función social que justifique su pervivencia, una legítima de naturaleza asistencial que dinamice las sucesiones y que atienda las necesidades del individuo, más allá del mero tránsito intergeneracional de la riqueza y del patrimonio familiar, en que se ha visto sustentado el Derecho sucesorio por causa de muerte. Se trataría de una parte del patrimonio hereditario con una función social, incardinada a satisfacer urgentes necesidades de contenido económico que si bien no supondría que ese sector más necesitado de la familia pueda vivir con holgura económica, tras la muerte de

\footnotetext{
${ }^{12}$ Ejemplo de ello es la reciente XV Jornada Notarial Iberoamericana, celebrada a finales de mayo, del año 2012, en Madrid. En efecto, una de las conclusiones (la número 6) de la Comisión No 3 que se dedicó al estudio del Derecho de personas, familias y sucesiones. Experiencias en Iberoamérica, se ha dejado dicho que "Se sugiere revisar la función y cuantía de las legítimas hereditarias, privilegiando la libertad del testador y salvaguardando su aspecto asistencial”.
} 
quien hasta ese momento era su principal sostén, al menos pueda constituir un paliativo en este orden.

Si bien los primeros comentaristas del nuevo Código Civil cubano obviaron el término legitimario para hacer referencia al perceptor de esta parte del patrimonio hereditario, esta reticencia fue cediendo con el paso del tiempo y por el peso de los argumentos que la doctrina científica ulterior esgrimió a favor de la denominación. Posición que encontró eco en las sentencias del Tribunal Supremo primero ${ }^{13}$ y luego de los tribunales provinciales ${ }^{14}$ e incluso en algún dictamen de la Dirección de Registros Civiles y Notarías del Ministerio de Justicia ${ }^{15}$.

\subsection{Caracteres de la condición de legitimario asistencial}

Intentemos, entonces, esbozar los elementos que caracterizan a este tipo concreto de legitimario, que le distinguen de la legitimarios clásicos y le individualizan. Apunto que este estudio se centra, más que en la legítima propiamente dicha, en el sujeto destinatario de ella, o sea, en el legitimario, visto desde la vertiente subjetiva del fenómeno.

\subsubsection{Excepcional}

La condición de legitimario asistencial es excepcional. Por naturaleza la mayoría de las personas que hoy habitan el planeta no son personas vulnerables económicamente, ni con discapacidad, ni dependientes económicamente ¡Ojo! Que tampoco es nada desdeñable el número de personas que se ubican en este círculo concéntrico. Un análisis objetivo me dará la razón de que la condición de legitimario asistencial es excepcional, hoy en día en la mayoría de las sucesiones que tramitamos los notarios no hay especialmente protegidos. Lo digo en términos matemáticos, con cierta relatividad, porque tampoco es que resulte de laboratorio la presencia de un legitimario en un sucesorio. La interpretación jurisprudencial

\footnotetext{
${ }^{13}$ Califica la existencia de una legítima a favor de los "herederos" especialmente protegidos, la cual ha de mantenerse íntegra, en respeto a su intangibilidad cuantitativa la Sentencia No 314, de 12 de mayo de 2005, primer Considerando, de la Sala de lo Civil y de lo Administrativo del Tribunal Supremo (ponente González García). Con similar sentido, en un supuesto de preterición, la Sentencia No 317, de 12 de mayo de 2005, primer Considerando (ponente González García) de la propia Sala. Alude como legitimarios al referirse a los "herederos" especialmente protegidos en un caso relativo a la inoficiosidad de las donaciones la Sentencia No 58, de 23 de marzo de 2009, primer Considerando, Sala de lo Civil y de lo Administrativo del Tribunal Supremo (ponente González García). Para hacer referencia a la preterición de los legitimarios, de la propia Sala, la Sentencia No 395, de 27 de diciembre de 2010, único Considerando (ponente Acosta Ricart).

${ }^{14}$ En un supuesto también de preterición se hace alusión al deber de legítima en la Sentencia No 13, de 26 de marzo de 2010 (proceso ordinario), tercer Considerando, de la Sala Segunda de lo Civil y de lo Administrativo del Tribunal Provincial de Ciudad de La Habana (ponente Insua Gamboa).

${ }^{15}$ Así, a guisa de ejemplo, el dictamen No $1 / 2010$ de 12 de febrero, sobre la posibilidad de que el caudal hereditario deferido a la muerte de una persona, pueda adjudicarse por sus herederos a través de varias escrituras públicas.
} 
EN LA BÚSQUEDA DE UN ROSTRO PARA EL BOCETO DEL LEGISLADOR: LA CONDICIÓN DE “HEREDERO” ESPECIAMENTE PROTEGIDO (LEGITIMARIO ASISTENCIAL) EN LA INTERPRETACIÓN DEL TRIBUNAL

de casos resueltos en este orden no es despreciable ${ }^{16}$. En el preámbulo del Código Civil y a modo, si se quiere decir, de interpretación auténtica, el propio legislador hace referencia a ello cuando expresa: “... en el ámbito del Derecho hereditario, (se) establece la libertad de testar, que sólo se ve limitada a la mitad de la herencia cuando existen herederos especialmente protegidos que hayan estado al amparo del testador", o sea, el principio que incardina el Derecho sucesorio cubano es el de la libertad de testar, la limitación de ésta es excepcional, pues excepcional también lo es la condición de legitimario, al cualificarse ésta y ser de apreciación judicial o notarial el cumplimiento, a la muerte del testador, de los presupuestos para revestirse de esta condición o cualidad. Acentuada, además, por la Sala de lo Civil y de lo Administrativo del Tribunal Supremo en algunas de sus sentencias, entre las que destacan la Sentencia No 484, de 31 de julio de 2003, segundo Considerando (ponente Acosta Ricart) al expresar que "... debe entenderse que la novedosa institución del heredero especialmente protegido que tutela nuestro Código Civil, deviene ante todo limitación al soberano derecho de testar libremente, de donde sólo por causas especiales y fehacientemente demostradas puede someterse a cuestionamiento el libre ejercicio de la facultad de una persona de disponer libremente sobre sus bienes para después de su muerte".

\subsubsection{Tuitiva o protectora}

El legitimario cubano, a diferencia de cualquier otro legitimario, lo es no sólo porque es perceptor de una parte del acervo hereditario, como pars bonorum, como comunero hereditario, con derecho a una parte del activo hereditario. No se trata de un acreedor ni tampoco de un alimentista. Su condición de legitimario tiene un fin tuitivo, protector en razón o bien de una discapacidad permanente de tipo intelectual de moderada a severa, o de una discapacidad sensorial o física o psíquica, de moderada a profunda, que le impida ejercitar sus potencialidad y capacidades, de modo que en comparación con los demás pueda obtener recursos económicos que le permita satisfacer sus más apremiantes necesidades económicas, o haya recibido por otros conceptos como el de herencia o de donación. Un patrimonio con entidad suficiente para la satisfacción de esas necesidades, que a mi juicio pueden ir más allá de aquellas propias, vinculadas con los alimentos en un concepto técnico, sino que podrían entenderse en la satisfacción de necesidades espirituales y estéticas del individuo que le permitan su integración como un ser social más.

No es una condición que esté vinculada con exclusividad con la sangre o el matrimonio, aunque la una o el otro, sean un presupuesto, a modo de alternativa, que hoy en día, resulten sine que non para superar el test de la especial protección.

\footnotetext{
${ }^{16}$ Colígese de la última edición del Código Civil de la República de Cuba, Ley No 59/1987, 16 de julio, anotado y concordado por Leonardo B. Pérez Gallardo, La Habana: Ciencias Sociales, 2011, y de las acotaciones jurisprudenciales a los artículos 492, 493 y 495 que en él se contienen.
} 
Hay que probar que además de tales requerimientos se cumplen los otros dos, a modo de yuxtaposición, según la exigencia que con tono imperativo reclama el legislador del Código Civil en los pocos trazos de su boceto y en lo que tantas veces ha insistido el Tribunal Supremo en los razonamientos de los considerandos de sus sentencias en función develadora del rostro de la figura en estudio. En su Sentencia No 232, de 24 de marzo del 2003, primer Considerando (ponente Acosta Ricart), se deja sentado que la recurrente "... no aportó ninguna prueba encaminada a demostrar tener tal cualidad, pues debe señalarse que en su caso no basta con ser la cónyuge sobreviviente del mismo, sino además no estar apta para trabajar $y$ haber dependido económicamente de aquél (...)". Luego, mucho más explícito en la Sentencia No 484, de 31 de julio del 2003, segundo Considerando, de la propia ponente, al dejar sentado que "... la aplicación del precepto señalado como infringido (artículo 493) requiere la concurrencia simultánea e inequívoca de los tres requisitos exigidos, en este caso, ser cónyuge sobreviviente del causante, no estar apto para trabajar y dependencia económica del testador, debiéndose abundar en el sentido que la omisión de uno solo de los mencionados, hace inaplicable el precepto (...)".

\subsubsection{Transitoria}

Las circunstancias que cualifican la condición de legitimario asistencial, son por regla general transitorias, como lo es la minoridad o como lo pueden ser ciertas discapacidades o la situación de dependencia o vulnerabilidad económica. Incluso, personas con discapacidad intelectual severa o profunda, pueden depender económicamente de una persona y en un momento dado cesar esa dependencia por disponer de un patrimonio que en el orden económico le permita tener cubiertas todas sus necesidades. No necesariamente hay perennidad en la cualidad de legitimario asistencial, y aun siendo ésta continua, a la muerte de ese sostén económico, se dependerá económicamente de otra y así sucesivamente. Se trata de circunstancias coyunturales, temporales, que se deben hacer coincidir con el momento del fallecimiento de aquella persona de la cual se reclama la condición de legitimario y, en consecuencia, la legítima que en Derecho le corresponde. $V . g r$, durante la minoridad se es especialmente protegido con respecto de ambos progenitores y esta circunstancia pudiera sobrevenir otra vez al arribarse a la mayoría de edad, cuando por no haberse vinculado laboralmente, deviene cierta enfermedad con efectos discapacitantes que hace a la persona que hasta ese momento ya había dejado de serlo por haber tenido aptitud para trabajar, nuevamente dependiente económicamente de su progenitor o progenitora, o de ambos a la vez. Esto hace intermitente la condición, ergo, más controversial en algunos casos su apreciación judicial.

Criterio que ha sido también compartido por la Sala de lo Civil y de lo Administrativo del Tribunal Supremo al apreciar los requisitos exigidos ex lege para 
EN LA BÚSQUEDA DE UN ROSTRO PARA EL BOCETO DEL LEGISLADOR: LA CONDICIÓN DE “HEREDERO” ESPECIAMENTE PROTEGIDO (LEGITIMARIO ASISTENCIAL) EN LA INTERPRETACIÓN DEL TRIBUNAL

adquirir la condición de especialmente protegido. En su Sentencia No 75, de 31 de marzo de 2009, segundo Considerando (ponente Díaz Tenreiro), la Sala expresa que para que el tribunal aprecie la condición de especial protección, amén del vínculo parental o conyugal con el causante, “... se demanda además la dependencia económica del causante y la no aptitud para trabajar-lo que le incorpora cierto carácter transitorio-", ello apoyado en la doctrina científica que se había pronunciado con anterioridad, entiéndase esta transitoriedad como temporalidad, eventualidad. Ese carácter transitorio, que como expresé, debe subsistir al deceso del testador, lleva consigo el control ex post por parte del notario o del juez al momento de la partición y adjudicación de la herencia, del cumplimiento de los requisitos para obtener la especial protección como también ya he explicado ${ }^{17}, \mathrm{y}$ que no es superable por un acuerdo entre los herederos concurrentes, aun cuando admitan que quien, reconocido como especialmente protegido por el testador por reunir en aquel momento todos los presupuestos para revestirse de esta condición, pueda adjudicarse la legítima aun y cuando a su deceso no se cumplan con todas y cada una de dichas exigencias, pues la sola voluntad de los herederos o legatarios concurrentes no puede hacer especialmente protegido a quien ex lege no lo es al deceso del testador. Si cesaron los presupuestos legales antes del deceso del testador, también finiquitó la especial protección. Las normas de ius cogens no son moldeables por la voluntad de los herederos, ni tan siquiera por la del testador que no le es dable impedir ese control ex post por parte del notario o del juzgador.

\subsubsection{Intransmisible}

La cualidad o condición de legitimario asistencial se hace depender de muy particulares circunstancias que se dan en el sujeto. El legislador le atribuye un carácter excepcional, en consecuencia es intransmisible. Si se tenía esa cualidad al momento del deceso del testador y se fallece después, entonces por mal que nos pese, se entiende adquirido el derecho y transmitido a sus respectivos herederos, ya que se ha incorporado previamente en el patrimonio del fallecido. Entenderlo de otra manera supondría adherirnos a la tesis que hoy, no niego pudiera tener defensores, de entender adquirida la cualidad o la condición de legitimario asistencial si los requisitos que le sustentan se tienen no sólo a la muerte del testador, sino aún después, al momento de la adjudicación hereditaria, pero ello supondría subjetivizar demasiado la apreciación notarial o judicial del cumplimiento de tales requerimientos y hacerlos depender no de un hecho tan palpable y objetivo cual es la muerte de una persona, y sí del cumplimiento de ciertos requisitos formales o de legitimación que se hacen necesarios para fallar un proceso judicial o autorizar una escritura pública de adjudicación hereditaria, y que pueden ser de tan diversa índole que sería necesaria una investigación ad hoc sólo para hacer un inventario

\footnotetext{
${ }^{17}$ Vid. sobre el tema Pérez Gallardo (2011b).
} 
de ellos, que además pueden escapar de cualquier grado de diligencia -aun el máximo-, que pudiera exigírsele al pretenso legitimario en hacer efectivo cuanto antes el revestimiento de su condición de especialmente protegido. En conclusión, creo justo que se fije como momento para apreciar la especial protección el del deceso del testador, lo cual motiva que ha de entenderse adquirida la cualidad en ese momento ${ }^{18}$, lo que acontezca después no sería privativo de la pérdida de la adjudicación hereditaria, salvo la aplicación del artículo 470 del vigente Código Civil o la del artículo 2 de la Ley No 989/1961 por razones que también he explicado en trabajos anteriores y que vienen de la mano de circunstancias de naturaleza meramente políticas que rebasan cualquier interpretación jurídica stricto sensu ${ }^{19}$.

\subsubsection{Renunciable}

$\mathrm{Al}$ ser por esencia el derecho a ser reconocido como especialmente protegido renunciable, desde la muerte del causante de la sucesión, el legitimario asistencial puede renunciar al derecho deferido a su favor, ya sea a título de herencia, o lo haya sido a título de legado (vid. artículos 524, 527 y 504 del Código Civil), siempre que lo haga en el plazo de la ley, que para el legatario se aplica por analogía legis el mismo del artículo 527.1 a) ${ }^{20}$. Nada le priva renunciar a la legítima. Renunciado el derecho del legitimario, desaparece el peso que gravita sobre los herederos voluntarios instituidos o legatarios nombrados que pueden adjudicarse la herencia

\footnotetext{
${ }^{18}$ Resulta interesante la Sentencia No 46, de 29 de enero de 1999, de la Sala de lo Civil y lo Administrativo del Tribunal Supremo que motivó un comentario de quien escribe estas páginas, en un supuesto muy peculiar en que los extremos enjuiciados era si la condición de especial protección que dispensa la ley a los padres del causante (en la sucesión ab intestato según artículo 516 del Código Civil) puede reconocerse aún después del fallecimiento de éstos, y en consecuencia si es transmisible vía mortis causa a los herederos testamentarios instituidos por los padres con especial protección en sus actos de última voluntad, la atribución patrimonial de que son merecedores en la sucesión intestada, a la muerte del hijo del que dependían económicamente, dada su falta de aptitud para trabajar. En la ocasión, la Sala deja sentado que la institución de los herederos especialmente protegidos es propia de la sucesión testamentaria. En la sucesión ab intestato sólo se les reconoce a los padres con especial protección (dependientes económicamente del causante y no aptos para trabajar) el derecho de ser incluidos como un heredero más en el primer llamado, derecho que tiene un carácter personalísimo al estar indisolublemente ligado a su titular, a los fines de tutelarlos patrimonialmente, no siendo, en consecuencia, dable su reconocimiento después de su muerte, como pretendía la heredera testamentaria de la madre con especial protección que no había sido incluida como tal en la declaración de heredero ab intestato del hijo, a pesar de que ciertamente lo era. Vid. Pérez Gallardo (2000), passim.

${ }^{19}$ Vid. Pérez Gallardo (2004a), pp. 161-167; Pérez Gallardo (2010a), pp. 68-76, y Pérez Gallardo (2010b), pp. 195-197.

${ }^{20}$ Vid. también el dictamen No 4/2008 de 15 de octubre, de la Dirección de Registros Civiles y Notarías del Ministerio de Justicia (en archivo del autor) que interpreta las normas del Código Civil en materia de legados y que hace extensiva vía analogía legis, las figuras del acrecimiento y la sustitución vulgar, así como la transmisión del derecho a renunciar al legado, a favor de los herederos del legatario que muere sin haber ejercitado en tiempo dicho derecho. Se colige de tal dictamen, aunque no lo diga expresamente, que por analogía legis es aplicable el plazo de caducidad establecido para la renuncia a la herencia, a la figura del legado. Vid., en concreto Apartado $11^{\circ}$.
} 
EN LA BÚSQUEDA DE UN ROSTRO PARA EL BOCETO DEL LEGISLADOR: LA CONDICIÓN DE “HEREDERO” ESPECIAMENTE PROTEGIDO (LEGITIMARIO ASISTENCIAL) EN LA INTERPRETACIÓN DEL TRIBUNAL

o adquirir el legado, en tanto que se entiende que la libre disposición del causante es el todo del caudal patrimonial, sin nada que penda en contra, dado que no hay legítima que atribuir al haber renunciado, lo cual lo pueden hacer ante notario, siempre que éste, tras el control ex post del cumplimiento de los requisitos de especial protección, compruebe que en efecto quien concurre ante él para renunciar a su condición de legitimario, realmente lo es, esto es, que está legitimado para renunciar porque realmente es un legitimario asistencial. De no cumplir al menos uno solo de los requisitos al momento del deceso del testador, no renunciaría, sino no tendría derecho a la legítima por no ser legitimario, circunstancia totalmente distinta, comprobable por acta de notoriedad ${ }^{21}$.

Por ello, reitero, es dable distinguir este supuesto de aquellos otros que también se han dado en la práctica notarial. Me refiero al caso en que el legitimario con pleno derecho, por cumplir con los requerimientos legales al deceso del testador, decide renunciar a la legítima, amparado en el artículo 5 del vigente Código Civil que permite la renuncia de los derechos que reconoce el propio Código, siempre que con ello "no redunde en menoscabo del interés social o en perjuicio de tercero", lo cual es perfectamente lícito, pues a nadie se le puede imponer la adquisición de un derecho en contra de su voluntad. El renunciante lo podrá hacer en escritura pública de renuncia a la legítima, siempre que pruebe su condición de legitimario, pues aun cuando tuviere interés en la renuncia, no escapa al control notarial del cumplimiento de los requisitos impuestos por el artículo 493.1 del Código Civil $^{22}$, ya que de lo contrario, sería nula la renuncia, en tanto hubiere renunciado quien no tenía derecho, por no ostentar al momento de la renuncia la condición o cualidad de legitimario. Incluso también lo podría hacer en la propia escritura de adjudicación hereditaria, interesada por los herederos voluntarios, en cláusula anterior, como paso previo a la adjudicación en favor de los herederos voluntarios, siempre que aporte las pruebas que permitieran al notario dar un juicio de legitimación del renunciante, esto es, que en efecto se trata de un legitimario del testador que en el acto pretende renunciar a la legítima deferida a su favor, con los efectos que en Derecho proceda.

\section{El “HEREDERO” ESPECIALMENTE PROTEGIDO EN LA INTERPRETACiÓN DEL Tribunal Supremo: En la búsqueda de los CONTORNOS DEL ROSTRO DE UNA FIGURA}

Sin dudas los "herederos" especialmente protegidos han ido asomando su perfil tras la labor interpretativa esencialmente de los jueces a partir del casuismo propio de esta manera de concebir las bases legales de su formulación. En 1988, con la entrada en vigor del Código Civil, el número de dudas era innumerable

\footnotetext{
${ }^{21}$ Vid. infra 5.

${ }^{22}$ Vid. infra 5.
} 
con el sentido que este vocablo tiene en el idioma español. Hoy, casi un cuarto de siglo después, muchas siguen en pie, y otras han devenido como consecuencia de la agudeza de estudios a todos los niveles que han hecho pensar y repensar a los estudiosos del Derecho sucesorio sobre la verdadera naturaleza de estos legitimarios asistenciales y, ante todo, a la riqueza que una visión práctica del Derecho pueda tener para cualquier académico el contacto con la realidad vivida y sentida.

\subsection{Menores, guarda y cuidado y especial protección}

La situación de minoridad suele estar asociada con la de especial protección. Una parte de los casos que son conocidos en el orden judicial resultan supuestos en los que, quienes reclaman especial protección son menores de edad, de modo que la litis tiende a trabarse no en torno al requisito del parentesco con el testador, fácilmente demostrable, ni tampoco a la ausencia de aptitud para trabajar, sino al concepto mismo de dependencia económica. ¿Se depende económicamente del padre o de la madre por el solo hecho de ser menor de edad? ¿Hay dependencia económica respecto de uno de los progenitores aunque fuere aquel que no tenía la guarda y cuidado? Dicho de otra manera: ¿El haber tenido el fallecido la guarda y cuidado sobre el menor es un presupuesto para reclamar la condición de legitimario de éste? ¿La desatención del progenitor respecto del hijo le libera de la protección legitimaria que el Derecho impone? ¿Se requiere la convivencia con el menor para que éste adquiera la condición de legitimario asistencial?

El Tribunal Supremo ha asumido en este orden posiciones interesantes que bien vale la pena tener en cuenta en estas cavilaciones. Unas que van desde considerar que la sola existencia de hijos menores, por el solo hecho de serlos, limita la libertad de testar. Así lo ha dejado dicho la Sentencia No 872, de 29 de diciembre de 2006, segundo Considerando (ponente Arredondo Suárez) al expresar que “... (Al) haber quedado justificado que el causante al momento de su deceso contaba con descendencia en minoría de edad y por ende beneficiarios de la condición de herederos especialmente protegidos, (...) (resulta) irrelevante lo argumentado en cuanto a la voluntad del causante para hacer valer las cuestionadas disposiciones testamentarias por ser preceptivo que la libertad de testar sólo alcanza la mitad de la herencia cuando existen, como en el caso, sujetos de especial protección". Criterio que puede ser contradicho si se lograre demostrar que el menor de edad, contaba al momento del deceso de su padre con un patrimonio suficiente para hacer frente no sólo a sus más apremiantes necesidades, sino para desplegar una vida en el orden económico con gran holgura. Se me ocurre pensar en la realidad cubana, el caso de que un menor hubiere heredado una fortuna de un pariente extranjero, administrada por sus padres, inconmensurablemente superior a todo el patrimonio de su fallecido padre. Por qué entonces considerarlo legitimario asistencial, si realmente no lo es, incluso con esa posición pudiera afectar la legítima de otros hijos menores de ese mismo padre que el destino no les deparó igual fortuna, y nunca mejor dicha la 
EN LA BÚSQUEDA DE UN ROSTRO PARA EL BOCETO DEL LEGISLADOR: LA CONDICIÓN DE “HEREDERO” ESPECIAMENTE PROTEGIDO (LEGITIMARIO ASISTENCIAL) EN LA INTERPRETACIÓN DEL TRIBUNAL

expresión. No obstante, entiendo la posición del juzgador, pues he descrito un ejemplo no muy común, pero sí que llamo la atención de que necesariamente minoridad no es igual que especial protección. En todo caso, en expresiones matemáticas sería como el límite en esta ciencia exacta, a saber: la minoridad tiende a ser vista como una posible y muy probable condición de legitimario asistencial, la minoridad tiende a la legítima asistencial, pero no siempre tiene que alcanzarla. No es algo preceptivo, sin más, habría en todo caso que probar la condición de legitimario.

Este criterio vendría sustentado desde fecha anterior a la sentencia que acabo de citar. Así, en un caso en que también se apreció la condición de especialmente protegido, el Tribunal Supremo en un pronunciamiento, a mi juicio, que extravasa el sentido que la legítima tiene en Cuba deja por sentado que “...los padres están obligados al sostenimiento de sus hijos hasta que alcancen la mayoría de edad, independientemente de que tengan suficiente solvencia económica o no, obligaciones $y$ deberes que comprenden el ejercicio de la patria potestad que le vienen impuestos por el artículo ochenta y cinco del Código de Familia (...)" (Sentencia No 637, de 17 de junio de 2001, único Considerando, ponente Arredondo Suárez), o sea, del sentido de este Considerando, es suficiente que se trate de un hijo menor de edad, para que los padres, por el solo hecho de su minoridad le tengan que atribuir la legítima, lo cual contradice la esencia asistencial que tiene la legítima en Cuba.

\subsection{Alimentistas y legitimarios asistenciales: ¿Círculos concéntricos?}

Otro de los tópicos es el relativo a la vinculación entre alimentos y legítima, que en ocasiones se les quiere acercar demasiado, al punto de darles una conexidad sustantiva, mayor de la que pudiera tener. $\mathrm{Al}$ respecto, me he referido en un comentario de sentencia que recientemente se ha publicado ${ }^{23}$, lo que retomo precisamente de dicho artículo. No cabe duda que la conexidad a la que aludo existe, en ambas instituciones hay cierto officium pietatis que no podemos soslayar, una razón tuitiva a personas carenciadas económicamente o desvalidas en el orden patrimonial, pero responden a circunstancias objetivas disímiles. Tómese en consideración que ni siquiera los sujetos beneficiarios de unos y otra son los mismos. Conforme con el artículo 124 del Código de Familia el círculo de alimentantes y alimentistas es más limitado que el de legitimarios, pues éstos se extienden hasta los sobrinos, que en cambio no tienen el deber de atribuir la legítima a sus tíos, por no ser legitimarios, y ni los unos ni los otros son entre sí parientes obligados a alimentos.

Sólo a modo de ejemplo, vale la pena citar dos sentencias en las que el Tribunal Supremo apoya la dependencia económica, en la obligación de dar alimentos. Así, en la Sentencia No 275, de 9 de abril de 2004, único Considerando (ponente Díaz Tenreiro), al interpretarse el sentido del requisito de la dependencia económica

\footnotetext{
${ }^{23}$ Vid. Pérez Gallardo (2011b).
} 
con el causante se deja dicho que "...conforme al señalado artículo cuatrocientos noventa y tres, es conjuntamente con la no aptitud para trabajar uno de los dos requerimientos que deben concurrir necesariamente para la configuración en la persona del presunto legitimario del carácter de especialmente protegido no puede tener la rígida interpretación que ofrece el casacionista, pues aun teniendo por sentado que el de cuius por las razones argüidas en los últimos meses de su vida se vio impedido de colaborar con la manutención de su menor hijo, tal impedimento no le liberaba de la obligación que por sentencia judicial firme le fue establecida, conforme a lo que regula el artículo cincuenta y nueve del Código de Familia, y conforme a ello siendo de las personas obligadas a dar alimentos se puede afirmar la existencia en el presente del requerimiento legal de dependencia económica (...)". Y la Sentencia No 307, de 29 de abril de 2005, en su segundo Considerando (ponente Acosta Ricart) en la que se afirma: “(...) visto que por parte de la recurrente se ha realizado una interpretación errónea del artículo cuatrocientos noventa y tres, inciso uno del Código Civil, al estimar que a los menores hijos del testador no les asiste el derecho a ser herederos especialmente protegidos de aquél, por el hecho de que su padre hubiere incumplido en mayor o menor medida, con la obligación de contribuir a su sustento obligación legal que le venía impuesta al ostentar la patria potestad sobre los mismos, en virtud del inciso uno del artículo ochenta y cinco del Código de Familia, la cual resultaba legalmente exigible de conformidad con el artículo ciento veintidós del propio Cuerpo Legal, y que podía llegar incluso a constituir ilícito penal, de modo que entenderlo como pretende la recurrente equivaldría a penar doblemente a los menores, al enervársele el derecho de ser herederos testamentario de su padre, precisamente por una causa de la cual fueron ellos los afectados (...)".

No obstante, como se ha dicho reiteradamente, nuestra legítima no es un supuesto de alimentos post mortem, como ciertos autores foráneos que han estudiado las normas de nuestro Código Civil aducen ${ }^{24}$. Se trata desde el punto de vista funcional de una legítima de freno, que se erige en una restricción a la libertad de testar del titular del patrimonio, con expreso reconocimiento de ella en el testamento a favor de sus beneficiarios y desde el prisma de su contenido,

\footnotetext{
${ }^{24}$ Algún autor, sin mucho detenimiento en su estudio, la ha incluido dentro de los llamados modelos "espurios" en que la legítima se aprecia como una obligación alimentaria post mortem. Vid. IANNACCONE, Atilio (1997). "Legittimari e eredi legittimi nel diritto comparato". En: Notariato, Rassegna sistematica di diritto e tecniche contrattuali, año III, No 5, septiembre-octubre, en concreto, pp. 470-471. El citado autor ubica, inexplicablemente, el modelo cubano junto al de México, China y Québec (Canadá), para lo cual afirma que: "La disciplina adottata in questi Paesi condiciona il vantaggio hereditario in favore di un succesibile -ovvero il suo ammontare-. All'esistenza di alcune situazioni di bisogno o dififficolà che fanno asumere alla 'riserva' un carattere fortemente 'alimentare". Con similar intepretación, pero desde otro ángulo de análisis, LeÑa Hernández, Rafael (2000). "El tráfico jurídico negocial y el discapacitado”. En: La protección jurídica de discapaces, incapaces y personas en situaciones especiales, Madrid: Editorial Civitas, $1^{a}$ Edición, p. 161, quien llega a decir que el legislador cubano ha dado entrada en materia sucesoria, en función tuitiva, "al cumplimiento mortis causa de la obligación de dar alimentos a favor de los hijos menores o discapacitados", extremo que sabemos no resulta exactamente ser así.
} 
EN LA BÚSQUEDA DE UN ROSTRO PARA EL BOCETO DEL LEGISLADOR: LA CONDICIÓN DE “HEREDERO” ESPECIAMENTE PROTEGIDO (LEGITIMARIO ASISTENCIAL) EN LA INTERPRETACIÓN DEL TRIBUNAL

Supremo DE CUBA

de una legítima pars bonorum, en tanto los legitimarios actúan como comuneros con derecho al activo líquido partible, pagándose aquélla con bienes ciertos y determinados del haz hereditario. De ello se colige que en el ordenamiento jurídico cubano, a diferencia de otros de nuestro entorno geográfico ${ }^{25}$, no existen los alimentos post mortem a favor de personas necesitadas, sino una clara y evidente legítima pars bonorum y que si bien los sujetos atributarios de los alimentos

\footnotetext{
${ }^{25}$ Así, artículo 1141 del Código Civil de El Salvador que regula las asignaciones alimenticias, los artículos 979, segundo párrafo, artículos 1147.1, 1148 y 1149, todos del Código Civil de Honduras, reguladores de las asignaciones alimenticias, las cuales junto a la porción conyugal son calificadas como asignaciones forzosas, igual tratamiento que da el Código Civil de Nicaragua en sus artículos 1197.1 y 1198 a 1200. El Código Civil de Panamá en su artículo 778 reconoce también el principio de la libertad de testar que tendrá como cortapisa el reconocimiento de los alimentos a favor de los hijos, de los padres o el cónyuge, siempre que al momento de la muerte del testador éstos no tuvieren bienes bastantes (vid. artículos 778, 813 sobre los alimentos a favor del cónyuge sobreviviente, artículos 814 al 817 en relación con los hijos, artículo 1204 sobre la liquidación de la sociedad legal de gananciales y el derecho de alimentos del cónyuge y de los hijos).

El Código Civil de Costa Rica establece en su artículo 595 el derecho de alimentos a favor de los hijos menores, mayores incapacitados, los padres o el cónyuge o compañero de hecho, siempre que al fallecimiento del causante estuvieren necesitados económicamente.

Ha dicho la jurisprudencia de este país centroamericano (Tribunal primero civil, voto No 528, de las 8.20 a.m. de 21 de mayo de 2003 que "En materia de sucesiones testamentarias, en virtud de las limitaciones a la libre testamentificación, los alimentos deben quedar asegurados. Asi lo dispone el artículo 595 del Código Civil, norma que establece un crédito alimentario a favor de los hijos, padres y consorte, desde luego en caso de no quedar asegurados en las disposiciones del testamento. En esa hipótesis, los acreedores deben promover un incidente de pago de alimentos y no un incidente de pensión alimenticia. La distinción es importante porque no se trata de fijar una pensión en los términos del derecho de familia. El crédito alimentario lo regula el citado numeral 595 del Código Civil y la pensión alimenticia en el 939 del Código Procesal Civil. El primero tiene como supuesto un testamento donde no se aseguran los alimentos y, en vía incidental con dictamen pericial, la finalidad es reservar un monto suficiente para cubrir la alimentación. El segundo depende de que la sucesión produzca rentas y se entregue a los herederos, por concepto de alimentos, hasta la cantidad que respectivamente pueda corresponderle por cuota hereditaria. En el caso del 595 del Código Civil el reclamo lo hace quien no es heredero y por ese motivo se convierte en acreedor alimentario, cuyo monto total se define en el incidente con el consecuente pago prioritario, todo a pesar de lo dispuesto en el testamento. Lo previsto en el numeral 939 del Código Procesal Civil es diverso, pues la pensión alimenticia la pide un heredero pero como parte de lo que le pueda corresponder en la distribución final'. Vid. Alpízar Rojas, María del Pilar (2010). Análisis del artículo 595 del Código Civil de Costa Rica a la luz de la jurisprudencia costarricense: ¿Una verdadera limitación a la libertad de testar? Tesis de grado, Universidad de Costa Rica, Facultad de Derecho, sede de Occidente. Disponible en: <www.iij.ucr.ac.cr/download/file/fid/425> [consulta: 1 agosto 2012], en nota 104, p. 120. Esta autora hace un agudo análisis de la figura de estos alimentos forzosos en el Derecho de su país, abogando por un sistema de legítimas, calcado del modelo español, sin más cortapisas. Su visión es crítica, pues considera que los alimentos regulados en el artículo 595 del Código Civil no resultan verdaderamente una cortapisa efectiva a la libertad de testar. A su juicio (p. 208), esta norma legal “... no logra su fin cual es la protección de la familia, pues pretender limitar la voluntad del testador con la simple expresión 'con tal de que' resulta erróneo e inconsistente (al) presentarla como una limitación para el causante puesto que tropieza con los alcances del Derecho de Familia y con el Derecho Sucesorio con respecto a los acreedores alimentarios a quienes se les otorga un crédito con privilegio general, pero ese crédito no le garantiza con respecto a otros acreedores un privilegio especial.

En el caso de que se quebrante la advertencia que hace la norma 595 del Código Civil no se producirá invalidez alguna al testamento, por consiguiente según el artículo 835 del Código Civil no existen elementos esenciales en su constitución que lo invaliden", lo cual hace muy endeble la verdadera protección de tales acreedores alimentarios.
} 
pueden hacerse coincidir con los legitimarios, el círculo de los legitimarios es más reducido que el de los alimentistas. Además de que el alimentista tiene un crédito frente al alimentante, que se paga esencialmente en dinero, aunque como establece el Código de Familia en su artículo 134, puede tratarse de una obligación facultativa, bajo ciertas precauciones legales, dado que "El obligado a prestar alimentos podrá, a su elección, satisfacerlos pagando la pensión que se fije o recibiendo y manteniendo en su propia casa al que tiene derecho a ellos. Esta última forma de prestar alimentos sólo procederá si no se afectan disposiciones relativas a la guarda y cuidado del alimentista y no existen impedimentos de orden moral o material', en tanto la legítima asistencial se paga en bienes concretos de la herencia, de modo que el legitimario actúa como un comunero más, teniendo a su favor la actio familiae ercinscundae.

\subsection{La posición de estudiante universitario no condice con la especial protección en sede sucesoria}

Durante mucho tiempo se debatió la posición del estudiante universitario en el escenario de los "herederos" especialmente protegidos. Posición que hoy día ha quedado superada tras el importante fallo judicial contenido en la Sentencia No 218, de 31 de mayo de 2011, de la Sala de lo Civil y de lo Administrativo del Tribunal Supremo, de la cual fue ponente Acosta Ricart. Los extremos enjuiciados en dicho fallo judicial se concretan en la posibilidad de que un notario autorice una escritura pública de aceptación y adjudicación de herencia testamentaria, sin que comparezca en ella el hijo del testador, a quien éste le atribuyó la legítima, si a su muerte ya era mayor de edad y estaba cumpliendo el servicio militar activo, con posibilidad de continuar estudios universitarios, habiendo estado incluso durante ese período contratado laboralmente. Ante lo cual dice el Alto Foro que reconocido un hijo menor de edad por el testador como "heredero" especialmente protegido al momento del otorgamiento del testamento, pero incumplidas las exigencias contenidas en el artículo 493 del Código Civil para estimar en su persona esa condición, resultaban al momento de testar futuras e inciertas, concretamente la falta de aptitud para el trabajo y la dependencia económica respecto al testador; y es que al ocurrir el deceso de éste, momento en que deben subsistir, para entonces ya era mayor de edad y en plena aptitud para trabajar, de modo que carecía de los presupuestos legales de la especial protección, pues optó por continuar vinculado al Sistema Nacional de Educación al habérsele asignado una carrera universitaria, lo cual se refuerza con la modificación del régimen laboral en nuestro país, apertura que permite a los estudiantes simultanear sus estudios con la realización de un trabajo remunerado, de modo que con ello se desvanece la posición por algunos esgrimida en cuanto a estimar a los estudiantes vinculados al Sistema Nacional de Educación como herederos especialmente protegidos. 
EN LA BÚSQUEDA DE UN ROSTRO PARA EL BOCETO DEL LEGISLADOR: LA CONDICIÓN DE “HEREDERO” ESPECIAMENTE PROTEGIDO (LEGITIMARIO ASISTENCIAL) EN LA INTERPRETACIÓN DEL TRIBUNAL

Supremo DE CUBA

Nadie ha dudado nunca de que el estudiante universitario que no tiene trabajo remunerado y que hasta fecha reciente no lo podía tener, podía cumplir con el requisito de la dependencia económica, $v$. gr., con respecto de sus progenitores, pero siempre resultó muy polémico sustentar que en ellos también se cumplía la no aptitud para trabajar. Como deja esclarecido la sentencia como ninguna otra, se trata de una posibilidad, de una elección, lógica y acertada, pero que no condice con la condición de legitimario, motivo que le impulsa a la jueza ponente a expresar en el segundo Considerando de la sentencia in commento, para combatir el cumplimiento del requisito de falta de aptitud para trabajar, que "... al ocurrir el deceso del testador, momento en que las mismas deben darse (se refiere a las exigencias legales ex artículo 493.1 del Código Civil), para entonces el inconforme ya era mayor de edad, y en plena aptitud para trabajar, pero carecía de actitud para hacerlo, pues en su caso optó por continuar vinculado al Sistema Nacional de Educación al habérsele asignado una carrera universitaria, esa fue su elección". Es decir, se trata de una decisión pensada, razonada, justa, adecuada, pero una opción que le lleva a mantener durante una etapa de su vida una situación económica menos holgada, aun cuando desde el año 2009, con la aprobación del Decreto-Ley No 268/2009, de 26 de junio, "Modificativo del régimen laboral", se admite la posibilidad en Cuba de que aquellos jóvenes que tengan 17 años de edad o más, sin vínculo laboral, matriculados en los cursos regulares de los niveles medio superior y superior, puedan vincularse laboralmente y percibir el salario que les corresponda por el trabajo que realicen, siempre que con ello no les afecte o limite en su rendimiento docente (vid. artículos del 11 al 13). Lo que, a su vez, le lleva a decir al Alto Foro en el tercer Considerando de esta sentencia que "con esa apertura que permite a los estudiantes simultanear sus estudios con la realización de un trabajo remunerado, se desvanece la posición por algunos esgrimida en cuanto a estimar a los estudiantes vinculados al Sistema Nacional de Educación como herederos especialmente protegidos". Es decir, si el estudiante universitario puede trabajar en sesión contraria a aquella en la que recibe clases o incluso todo el día, optando por otras modalidades de enseñanza como la educación a distancia o los cursos para trabajadores, no hay razón para incluirles bajo el ropaje de la condición de legitimario asistencial, pues nunca cumpliría con el requisito de no aptitud para trabajar pues ésta la tendría, sólo que ha optado por una modalidad de enseñanza acorde con su proyecto de vida y sus perspectivas profesionales, pero no por ello puede reclamar de los parientes o del cónyuge, que le atribuyan una legítima sucesoria respecto de la cual ningún derecho tiene. Sencillamente, en tal supuesto se carece de derecho subjetivo y, en consecuencia, de legitimación activa para impugnar un testamento en el que no se le hubiere reconocido como legitimario o, tal y como acontece en el caso, una adjudicación hereditaria, en la que no tiene participación. De este modo, actuó conforme a Derecho el tribunal de instancia cuando en su sentencia declaró con lugar las excepciones perentorias alegadas por la contraparte en la contestación a la demanda, de falta de legitimación activa y carencia de derecho subjetivo. 


\subsection{Matrimonio, separación de hecho y condición de legitimario}

En este ir y venir de los trazos de nuestro pintor, no menos interesante lo ha sido el develar los vínculos que operan entre el matrimonio y la condición de legitimario. A priori, cabe apuntar que sólo aquel que demuestre su condición de cónyuge superstite, tras la formalización del matrimonio, aun con carácter retroactivo, o el reconocimiento judicial del matrimonio (vid. artículos 2, 18 y 19 del Código de Familia) no podrá adquirirse el derecho a la herencia por sucesión ab intestato. El matrimonio no sólo crea un conjunto de deberes y derechos de contenido personal (vid. artículos 24 al 28 del Código de Familia), sino también de contenido patrimonial (vid. artículos 29 y ss. de aplicación), ergo, la sola existencia del matrimonio no supone la condición de legitimario asistencial, pero sí el cumplimiento de uno de los presupuestos, o sea, el de ser cónyuge. De este modo, demostrado que aun y existiendo un matrimonio, jurídicamente hablando, si la convivencia dejó de existir, y con ello, las relaciones afectivas, puede ser prueba suficiente para que se desmorone el argumento de quien sostenga le sea atribuida judicialmente la condición de legitimario asistencial por el solo hecho de la subsistencia del vínculo legal (formal) del matrimonio. Así, se declara sin lugar el recurso de casación interpuesto por quien no fue favorecido con la especial protección sobre la base del incumplimiento del resto de los requerimientos legales exigidos por el artículo 493 del Código Civil en la Sentencia No 34, de 31 de enero de 2006, único Considerando (ponente Arredondo Suárez), cuando el Tribunal Supremo se explaya en el sentido de que "... aun cuando consta acreditada la participación del recurrente en la unidad económica del núcleo familiar que conformara con la causante en razón del matrimonio que fuera judicialmente reconocido, el hecho mismo de encontrarse apto para el trabajo remunerado al que, por demás, se encuentra vinculado y el no haber dependido económicamente de la causante, lo excluye de la condición de heredero especialmente protegido que con su interpretación personal de las normas sustantivas al respecto pretende imponer (...)"26.

\footnotetext{
${ }^{26}$ Posición que también refuerzan los tribunales de instancia. La Sala Segunda de lo Civil y de lo Administrativo del Tribunal Provincial de Ciudad de La Habana en su Sentencia No 27, de 30 de marzo de 2007 (Proceso Ordinario), segundo Considerando (ponente Alfaro Guillén) expresa: "no basta detentar la condición de viuda del causante, para el goce del beneficio que dispensa el estatus sucesorio de devenir heredero especialmente protegido, lo que podrá verificarse únicamente en aquellos supuestos en los cuales quien se considere dignatario de tal condición, demuestre fehacientemente encontrarse en las situaciones constitutivas de los requisitos legalmente exigidos al efecto".

Más ilustrativa resulta la Sentencia No 104, de 28 de diciembre de 2007 (proceso ordinario), único Considerando (ponente Torres Torres) de la propia Sala, en un supuesto de ruptura de hecho de la vida convivencial de la pareja por un período superior a los treinta años. Se trataba de un caso de matrimonio constituido legalmente pero con ruptura fáctica ininterrumpida que llevó a los cónyuges a rehacer su vida sentimental, pero sin romper nunca el vínculo legal marital. En este sentido se pronuncia la Sala de que “(...) al ocurrir el fallecimiento de la causante (...) el reclamante no dependía económicamente de ésta, por tanto no estaba obligada la testadora a reservar para el mismo la porción de la herencia que impone el artículo cuatrocientos noventa y dos punto uno del Código Civil para herederos especialmente protegidos, declarado como efectivamente hizo en el instrumento notarial examinado que respecto a ella no existían estos herederos, hecho
} 
EN LA BÚSQUEDA DE UN ROSTRO PARA EL BOCETO DEL LEGISLADOR: LA CONDICIÓN DE “HEREDERO” ESPECIAMENTE PROTEGIDO (LEGITIMARIO ASISTENCIAL) EN LA INTERPRETACIÓN DEL TRIBUNAL

Por el contrario, en la Sentencia No 80, de 29 de febrero de 2008, primer Considerando (ponente L. Hernández Pérez) se aprecia que “... concurre en la parte no recurrente la circunstancia de ser heredera especialmente protegida, ya que mantenía con el testador una unión matrimonial no formalizada, que cumplía los requisitos de aptitud legal, singularidad y estabilidad de la pareja durante el periodo comprendido desde (...), la que fuera reconocida judicialmente mediante sentencia firme, y por consiguiente con todos los efectos propios del matrimonio formalizado, por lo que tiene la condición de cónyuge sobreviviente que dependía económicamente del causante por ser ama de casa, careciendo de ingresos propios, además de no encontrarse apta laboral al tener cincuenta y siete años, edad que excede la establecida para que la mujer pueda obtener la jubilación (...)". El reconocimiento del matrimonio permitió que la parte no recurrente obtuviera la condición de "heredera" especialmente protegida, pero no sólo sobre la base del éxito de la demanda de reconocimiento judicial del matrimonio, sino sustentado en esencia en el cumplimiento, además del anterior requisito, del resto de los presupuestos o conditio iuris establecidas por el legislador. Se trataba de una ama de casa que siempre dependió económicamente del esposo ya que no se incorporó a trabajar, desarrollando el trabajo doméstico del hogar, quien al momento del fallecimiento de su esposo tenía 57 años, edad que en la fecha de la sentencia sobrepasaba la que establecía la legislación de seguridad social vigente entonces, para jubilarse ${ }^{27}$.

\subsection{Mayor de edad judicialmente incapacitado, internado en centro asistencial, y el reconocimiento de la condición de legitimario asistencial}

El concepto de dependencia económica ha de ser interpretado en sentido lato, y no en el riguroso y estricto de sujeción monetaria con respecto del causante de la sucesión, que implica sostén, habitación y recursos imprescindibles para procurarse la alimentación. De tratarse de un hijo mayor de edad, judicialmente incapacita-

\footnotetext{
que resulta cierto en tanto no basta para alcanzar la condición reclamada por el actor que fuese el cónyuge de la causante por matrimonio formalizado (...) sino que requiere para encontrarse incurso en tal especial condición de que su sustento dependiera de aquélla, lo que no se observa en el caso en examen, habida cuenta que desde que se produjo el rompimiento de la relación marital de la pareja (...) yéndose el demandante a residir fuera del domicilio conyugal por espacio de treinta años, periodo en el que la señora (...) estableció otra relación marital no formalizada con otro hombre con el que hizo vida común por veinticinco años, y aun habiendo regresado el actor a la vivienda (...) por petición del hijo de ambos, retorno que no significó el restablecimiento de la antigua relación de esposos; no tenían una vida en común y menos dependencia económicamente de la señora (...) quien tenía para sustento propio una pensión por jubilación obtenida por haber laborado durante muchos años para obtener su propia economía en una vida independiente de la persona con la que solo le unió un matrimonio formal luego del rompimiento de la pareja, existiendo entre ambos además una pésima relación interpersonal donde la testadora, por razón de su género fue víctima de conducta abusiva que llegó incluso al maltrato fisico por parte de quien ahora ocurrido el fallecimiento de dicha causante pretende (...) sin razón moral alguna obtener beneficio patrimonial ilegítimo en la sucesión mortis-causa (...)”.

${ }^{27}$ Recordemos que la Ley No 24/1979 estableció los 55 años para obtener la pensión ordinaria por jubilación en el caso de las mujeres, además de los 25 años de servicios.
} 
do, no ha de trascender el hecho de si este se encuentra sometido a un régimen de internado asumido por el Estado, porque ello supondría convalidar cualquier actuación de desidia o desatención por parte del padre a los deberes que como progenitor le corresponde sobre su hijo, entre ellos la atribución de una cuota de su patrimonio a su deceso en concepto de legítima asistencial, pues esta modalidad de legítima, tiene un fin tuitivo, protector, garantista de personas desvalidas, con independencia de que el Estado le cubra sus más apremiantes necesidades. Admitir lo contrario supondría eximir a los progenitores de la restricción impuesta ex lege, bajo el manto de normas de ius cogens, y desplazar este deber insustituible a manos del Estado, de modo que de seguir este razonamiento, obtendría una ventaja infundada el progenitor que no asumió en vida la atención de su hijo incapacitado, en tanto que con ello se liberaría además de la restricción que la legítima supone a la libertad de testar.

Precisamente sobre tal particular versó la Sentencia No 532, de 29 de diciembre de 2011, de la Sala de lo Civil y de lo Administrativo del Tribunal Supremo. En dicho fallo se discutió si cabe o no la nulidad de la institución de heredero testamentario, cuando el testador al momento de su deceso tenía un hijo judicialmente incapacitado por retraso mental severo, sometido a un régimen de internado en un centro asistencial estatal, a quien no reconoció como especialmente protegido en su testamento y no le atribuyó bien alguno como pago de la legítima asistencial, amén de las relaciones afectivas que tenía el causante con su hijo. Ante tales hechos enjuiciados, el Alto Foro deja sentado que aun tratándose de un hijo, judicialmente incapacitado, por retraso mental severo, internado en centro asistencial estatal, no goza éste de la cualidad de especialmente protegido, respecto de su padre, si no se acredita la responsabilidad económica que en vida tuvo el padre respecto de él, en tanto su internamiento hace al Estado responsable de su asistencia gratuita, al cubrir las necesidades elementales de sustento, habitación y vestido.

Precisamente el asunto sometido a consideración del Tribunal Supremo parte de un supuesto en el que el pretenso especialmente protegido es un hijo mayor de edad, judicialmente incapacitado. En un caso de esta naturaleza nada hay que discutir sobre la aptitud para trabajar, el otro requisito a modo de yuxtaposición, que exige el artículo 493.1 del Código Civil para asumir la condición de legitimario. Se trataba de una persona con retraso mental severo, motivo por el cual se le incapacitó, ergo, de que carecía de aptitud para trabajar, nada ni nadie jamás lo discutió. La situación se hace polémica sobre la posible dependencia económica de dicho incapacitado respecto de su padre.

La incapacitación supone el nombramiento de un tutor, lo cual en el caso recayó en la madre. De manera que, si bien el padre no ostentaba la representación legal del incapacitado, no deja de ser padre, con los deberes que ello implica en situación tan especial como la de que el hijo, aun mayor de edad, carece del ejercicio de la capacidad jurídica, además de un patrimonio que puede hacer frente a sus más apremiantes necesidades, porque si lo hubiera tenido, conforme con el Derecho 
EN LA BÚSQUEDA DE UN ROSTRO PARA EL BOCETO DEL LEGISLADOR: LA CONDICIÓN DE “HEREDERO” ESPECIAMENTE PROTEGIDO (LEGITIMARIO ASISTENCIAL) EN LA INTERPRETACIÓN DEL TRIBUNAL

cubano no clasificaría dentro de los legitimarios, pero no era el caso. Ahora bien, la particularidad que le da ribetes interesantes a este asunto es que el incapacitado estaba sometido a un régimen de internado en centro asistencial del Estado, con lo cual se asume por dicho centro la alimentación, sustento, habitación y vestido del incapacitado, propio de los centros de esta naturaleza en el país. A fin de cuenta quien lo está asumiendo es el Estado, pues el centro no es persona jurídica y consecuentemente no tiene patrimonio propio.

Dadas estas circunstancias habría que dilucidar si una persona sometida a este régimen de internamiento asistencial, deja de estar bajo el sostén económico de su progenitor. Dicho hasta aquí, es cierto, literalmente hablando no se depende económicamente de los padres, sino del Estado. Las más imperiosas necesidades las cubre el Estado a través de ese centro asistencial, lo cual no supone que los progenitores se deben desentender, pues en tales circunstancias han de darle apoyo emocional, psíquico y afectivo al hijo. La familia no debe renunciar nunca al papel que le corresponde y que además le viene impuesto.

La legítima que reconoce el Derecho cubano, si bien es excepción y no regla, ha de entenderse como un paliativo a la especial situación de su destinatario, sobre todo de cara a sus derroteros tras la muerte de sus familiares más cercanos que son su sostén. Una persona sometida a un régimen de internado en un centro asistencial necesita esparcimiento, períodos vacacionales fuera del centro, su propia vivienda y con ello lo que resulta indispensable para mantener una vida en el hogar, aun sean períodos cortos los que esté fuera del mencionado centro, lo que además no tiene por qué ser permanente, aun cuando en el caso sometido al foro, el incapacitado llevaba cerca de 29 años bajo ese régimen. Precisamente para hacer frente a esas necesidades, que no tienen carácter extraordinario, se trata de lo común y ordinario que una persona puede hacer, es que se necesita de un soporte patrimonial. Ni la discapacidad mental ni la incapacitación judicial incluso, privan a un ser humano de la distracción y del entretenimiento, necesidades también que deben ser asumidas por quienes correspondan. Por ello, sabiamente el legislador no enunció a modo de numerus clausus el contenido de la dependencia económica del causante. A mi juicio, y en ello discrepo del juzgador, en aras de una verdadera protección a las personas con discapacidad, la legítima a que conduce el legislador ha de entenderse en tiempo futuro, si bien el artículo 494 del Código Civil permite su atribución por cualquier título, con lo cual cabría su pago por donación en concepto de anticipo de legítima ${ }^{28}$. No se trata únicamente de que el legitimario dependía del causante, lo cual es cierto hay que probar, sino de cómo esa legítima,

\footnotetext{
${ }^{28}$ El legislador en el artículo 494, reproduce el artículo 815 del Código Civil español, sin tener en cuenta que el modelo legitimario que incluye en el Código se distancia del español, en su función esencialmente asistencial, motivo por el cual debiera haberse previsto que su pago sólo fuera posible a la muerte del causante, con ello se garantizaría su disfrute post mortem, momento en el cual se carece por el causahabiente protegido de la persona que hasta el momento era el soporte para la satisfacción de sus más imperiosas necesidades de contenido económico.
} 
traducida en la mitad del patrimonio del causante deferido a favor del legitimario, puede hacer frente a la cobertura de las ulteriores necesidades patrimoniales de éste, que no debe recaer, en principio, en manos del Estado. No es el Estado quien debe asumir esa responsabilidad, sino la familia. No hay que invertir los roles, el Estado auxilia a la familia, contribuye con la familia, coopera con la familia, pero no a la inversa, aun en el supuesto de que la persona esté sometida a un régimen de internado de un centro asistencial. No es función netamente estatal, así se trate del Estado de bienestar.

El plexo de valores de una norma legal no puede apartarse por una férrea interpretación de los operadores del Derecho. El ordenamiento jurídico no es sólo una amalgama de preceptos legales stricto sensu, en él desempeñan una actuación, nada secundaria, los valores, y ellos deben ser rescatados y situados en el lugar que les corresponde. En el último de los apartados de la parte expositiva (por cuantos), el legislador del Código Civil deja esclarecido que este cuerpo normativo ha de "estimular la ayuda mutua entre los miembros de la sociedad", lo cual no es sino expresión del principio de solidaridad en las relaciones jurídicas civiles, dentro de las que se sitúan las de naturaleza sucesoria. Cualquier interpretación de las normas contenidas en el Código Civil han de ser conforme con este principio, inmanente a la sociedad cubana, y que más solidaridad que la que fomenta e incentiva el legislador de este cuerpo legal entre los miembros de la familia (ciertos parientes consanguíneos y el cónyuge) en sede sucesoria, cuando uno de ellos es dependiente o vulnerable económicamente, por disímiles razones, entre las cuales han de ubicarse ciertas discapacidades (en las que las intelectuales ocupan un sitial no menos significativo).

Una sentencia no sólo contiene la composición de una litis. Los jueces, quizás sin saberlo, ofrecen a través de las sentencias lecciones a sus destinatarios, que no son sólo las partes enfrentadas, no a modo de clase magistral, y sí como expresión de la experiencia acumulada con el decursar de los años. Las máximas de la vida tienen un valor no menos trascendente en los considerandos de una sentencia judicial, redoblado cuando ésta proviene del Alto Foro, cuyas líneas jurisprudenciales son seguidas por los operadores del Derecho y por supuesto por la doctrina científica. Una sentencia apegada al sentido estricto de una norma legal no cumple en mayor medida con el principio de legalidad, pues si para pronunciar un fallo los jueces se adhieren como la hidra a una interpretación gramatical o filológica de los términos empleados por el legislador, con lo cual sacrifican el sentido que la equidad exige, inmolan entonces también el propio sentido de la legalidad, pues una ley no sólo es lo que literalmente dice, sino lo que quiere cubrir, en ella hay que develar como hace el artista, el plexo de valores que le informan, y entre ellos se sitúa en sede sucesoria el de solidaridad familiar, cuya expresión más acabada hoy lo constituye la legítima asistencial a favor de personas discapacitadas o vulnerables económicamente, las cuales deben ser centro de atención del Derecho Civil en aras de una efectiva inserción 
EN LA BÚSQUEDA DE UN ROSTRO PARA EL BOCETO DEL LEGISLADOR: LA CONDICIÓN DE “HEREDERO”

social, en su plena realización como persona, y como sujeto de las más diversas relaciones jurídicas civiles, para lo cual la arista de naturaleza patrimonial que ofrece el Derecho sucesorio no deja de tener repercusión. Se trata, entonces, de que los jueces como boca de la ley, la apliquen, buscando ante todo el sentido de la racionalidad, la proporcionalidad y la justicia.

\subsection{Pensión por jubilación o viudedad y el derecho a la legitima asistencial: ¿Son incompatibles?}

El Tribunal Supremo ha utilizado una fórmula matemática, algo así como:

Pensión por jubilación o viudedad $¥$ condición de especialmente protegido

Es decir, si tienes atribuida una pensión por edad, en razón de la jubilación o una pensión por viudedad, a cargo ambas de la Seguridad Social, entonces, no tienes derecho a que te arropes con la condición de especialmente protegido, porque tienes sustento propio. Empero, ¿̇son acaso incompatibles la única con la otra? A mi juicio no, en lo absoluto. Se puede estar pensionado y a la vez depender económicamente de otra persona, pues las necesidades propias de esa persona hacen que la pensión no sea lo suficiente para cubrir con todos sus gastos y sea demostrable ante el órgano judicial que su pariente o cónyuge era el principal sostén económico y no la pensión, y que con esta pensión, tras el fallecimiento de aquél, no puede satisfacer sus más apremiantes necesidades de diversa índole. Casos de esta naturaleza no son tan excepcionales en la Cuba de hoy con los niveles que ha alcanzado la vida cotidiana. No obstante, para el Tribunal Supremo la solución es distinta, de ahí la rigidez con la que se valora el requisito de la dependencia económica. El Alto Foro ha hecho reiterados pronunciamientos en este orden, a saber:

En su Sentencia No 515, de 22 de julio de 2004, segundo Considerando, de la que fue ponente Arredondo Suárez, dejó dicho: “... sentado por la sentencia combatida que la recurrente siempre contó con ingresos económicos propios, consistentes primero en su salario como trabajadora y luego en la pensión por edad que al obtener su jubilación comenzó a percibir, una recta aplicación de los aludidos preceptos conduce a colegir que se trata de dos cuestiones distintas, cuales son, en primer orden la participación económica en el núcleo familiar del causante que la hizo beneficiaria en su momento de la pensión provisional por causa de su fallecimiento y luego de la pensión definitiva por igual concepto, con el derecho de opción que le franquea el precitado artículo dieciséis de la Ley número veinticuatro y, en segundo orden, la dependencia económica a que se contrae el apartado primero del artículo cuatrocientos noventa y tres de la ley sustantiva en la materia como presupuesto indispensable para que le sea reconocida la condición de heredera especialmente protegida, por lo que al no existir la aludida dependencia forzosamente ha de estimarse que no le asiste el derecho a tal especial protección y, por ende, al no encontrarse limitada la libertad de testar no puede ser cuestionada la eficacia del legado contenido en el impugnado instrumento público (...)". 
En su Sentencia No 317, de 30 de mayo de 2007, primer Considerando, de la que fue ponente Carrasco, casi también se hizo eco del anterior parecer al expresar que "... al quedar justificado en el pleito que ésta (la recurrente) disfrutaba de una prestación de la seguridad social a largo plazo, obvio resulta que no se encontraba en una situación que no podía valerse por si misma, sino que al acogerse a la pensión que disfrutaba dicho causante, ejercitó el derecho de opción que concede el artículo dieciséis de la Ley veinticuatro de Seguridad Social de veintiocho de agosto de mil novecientos setenta y siete (...)".

En la Sentencia No 58, de 23 de marzo de 2009, tercer Considerando, con ponencia de González García, de igual manera se aduce que “... no ha quedado demostrado que respecto a quien recurre, actora del proceso, concurran las condiciones personales que corporifican la especial protección a que se refiere el articulo cuatrocientos noventa y tres, apartado primero, letra $b$, del Código Civil, a cuyo efecto no basta encontrarse percibiendo una pensión por causa de muerte del régimen de seguridad social con motivo del deceso del causante, que se concede a determinados parientes con derecho a ello y no implica necesariamente una relación de dependencia económica (...)".

En la Sentencia No 322, de 29 de octubre de 2010, tercer Considerando, ponente Acosta Ricart, igualmente se invoca la existencia de una pensión por edad para rebatir la dependencia económica respecto del causante, afirma la Sala que “... denunciada la infracción del inciso c) del apartado uno del artículo cuatrocientos noventa y tres del Código Civil, tal vulneración no existe porque, sentado por la sentencia combatida que la progenitora del testador cuenta con medios propios de subsistencia por recibir pensión por edad, una recta aplicación del precitado precepto, conduce a colegir que carece del presupuesto de dependencia económica del causante que, al unisono con la ineptitud para el trabajo, exige la norma en cuestión para que se configure la institución del heredero especialmente protegido, lo que inequivocamente fuerza al rechazo del motivo".

Por último, en la Sentencia No 475, de 4 de noviembre de 2011, único Considerando de la primera sentencia, ponente Arredondo Suárez, declara con lugar el recurso de casación interpuesto contra la sentencia de instancia, sobre la base de una apreciación errada de la condición de especialmente protegida de la impugnante del testamento (en buena lid lo que debió impugnar el recurrente era la institución de heredero, vid. artículo 495.1 del Código Civil), por no estar legitimada para ello, al carecer de la condición de especialmente protegida, precisamente por ser titular de un pensión ordinaria por edad. A tal fin se dice que "... es cierto, como aduce el recurrente, que la Sala que dictó la sentencia interpelada infringe, por indebida aplicación, el apartado uno inciso b) del artículo cuatrocientos noventa y tres del Código Civil, puesto que al dictar fallo desestimatorio de la acción de nulidad del testamento notarial (...), se desentiende de la connotación que alcanza el hecho que sienta, referido a que la designada como heredera especialmente protegida es beneficiaria del Sistema de Seguridad Social, por disfrutar de pensión ordinaria por edad, circunstancia que 
EN LA BÚSQUEDA DE UN ROSTRO PARA EL BOCETO DEL LEGISLADOR: LA CONDICIÓN DE “HEREDERO” ESPECIAMENTE PROTEGIDO (LEGITIMARIO ASISTENCIAL) EN LA INTERPRETACIÓN DEL TRIBUNAL

denota que no dependía económicamente del causante y que carece por ende, de presupuesto básico para ostentar tal condición sucesoria, que en modo alguno puede asimilarse a la libertad de testar, en el entendido de que precisamente la institución en comento refrenda una limitación a tal prerrogativa con el fin de proteger a determinados parientes por su ineptitud para el trabajo y su dependencia económica del causante y, al desconocerlo la sentencia interpelada, incurrió en la vulneración denunciada, lo que fuerza a la estimación del motivo examinado (...)"29.

Del análisis de las sentencias citadas cabe colegir que en todos los casos, siempre que haya un mero resquicio, el Alto Foro no concede la condición de legitimario a quien al deceso del testador disfrutaba de una pensión a cargo de la Seguridad Social, lo que hace más palpable en la última de las sentencias dictadas en la que se deja inferir que el solo hecho de que la cónyuge era beneficiaria de la seguridad social, hace evidente que no podría interesar la condición de especialmente protegida, en tanto la pensión se erige en un obstáculo insalvable para que, además de pensionada, pueda revestirse en su favor la cualidad de legitimaria, como si ambas circunstancias fueran inexorablemente incompatibles, tal y como si se tratase de una fórmula de las ciencias exactas. De este modo, se olvida una vez más que en las ciencias jurídicas no operan los resultados preestablecidos de las ciencias exactas. La condición de legitimaria de una persona condice perfectamente con la de beneficiaria de una pensión por la Seguridad Social, cuando esta última no es el pivote patrimonial de una persona. Se trata en todo caso de una situación circunstancial que como tal debe ser valorada en sede judicial o notarial.

No obstante, en honor a la justicia, cuando ya casi concluyo estas páginas, he podido constatar un giro importante que hace el Tribunal Supremo en este orden en su Sentencia No 288, de 31 de julio de 2012, en su primer Considerando, de la cual fue ponente Arredondo Suárez, en un supuesto de sucesión ab intestato, en que en principio no hay reconocimiento de la figura de los legitimarios, salvo el atisbo previsto de los padres con especial protección, a quienes se les reconoce como herederos concurrentes en el primer llamado, a partes iguales con los herederos titulares, precisamente en razón de su especial protección (por dependencia económica y ausencia de aptitud para trabajar). La recurrente, en el recurso resuelto por el tribunal de casación, sustentaba la tesis de la no dependencia económica del padre respecto del causante, quien había sido incluido en el acta de declaratoria de herederos de su hijo, en razón precisamente de que no estaba apto para trabajar al deceso del hijo y dependía económicamente de él, requisito este último que alega no cumplir y en consecuencia no estar incluido entre los beneficiarios de la especial protección, motivo por el cual interesa la modificación del acta de declaración de herederos ab intestato, en el sentido de que dicho señor fuera excluido

\footnotetext{
${ }^{29}$ En todos los casos la negrita me pertenece.
} 
de la delación hereditaria, cuya expresión documental lo es la citada acta, como título sucesorio demostrativo.

En efecto, literalmente interpretado el precepto, el padre del causante en los últimos tiempos de vida de éste, no dependía económicamente de él, pues dada la enfermedad que le aqueja al hijo, le hizo estar sujeto a tratamiento de larga duración, que le impidió valerse por sí mismo, hasta el momento de su deceso. Empero, con total sentido de lógica, de racionalidad y de justicia, el Alto Foro declara sin lugar el recurso interpuesto sobre la base de sólidos argumentos, que suponen una interpretación correctora del artículo 516 del Código Civil (en el sentido de dar una interpretación extensiva a éste), al sustentar que "si bien el instituto en cuestión exige la yuxtaposición de requerimientos para estar incurso en la cualidad apuntada, no lo es menos que aunque dicho padre resultara protegido por el régimen de asistencia social, como persona no apta para trabajar y carente de familiares en condiciones de prestarle ayuda, existen elementos de juicio suficientes que determinan que tal suceso no quebrante el presupuesto de dependencia económica e incida en la condición de legitimario, en tanto se debió a especifico acontecimiento, dado por la propia ineptitud para el trabajo del causante, quien sufrió penosa enfermedad que lo hizo estar sujeto a tratamiento de larga duración, le impidió valerse por si mismo y finalmente le ocasionó la muerte, de manera que por razones objetivas estuvo impedido temporal y circunstancialmente de ofrecer de modo directo la protección económica y las atenciones que dispensaba a su progenitor, y por propia gestión obtuvo ayuda de los servicios sociales comunitarios e institucionales para éste, lo que denota el comprometimiento de todo tipo del descendiente con el bienestar de su padre, de ahi que se apartaría del criterio racional, justo y lógico que se acepte como buena una interpretación de la norma ajena a las vicisitudes de la vida y, consecuentemente, no puede estimarse la errónea apreciación de pruebas que injustificadamente le atribuye la inconforme".

Es interesante este pronunciamiento del Tribunal Supremo, en tanto reconoce que los padres con especial protección en la sucesión ab intestato son legitimarios, posición, no obstante, discutible en tanto que a su favor no se dispensa idéntica cuota a la que tenían derecho si el causante hubiera testado, si bien no cabe dudas que los padres con especial protección son herederos concurrentes del primer llamado, precisamente en atención a las circunstancias que se dan en ellos, de lo contrario de existir hijos, no heredarían. Vale la interpretación dada por el Alto Foro tendiente a la protección del padre, que va más allá del apego literal a la norma como suele acontecer en no pocas sentencias. La dependencia económica respecto del causante es una circunstancia muy relativa, coyuntural, apreciada ad hoc, con sentido de la proporcionalidad y de la lógica. Sólo así es posible lograr la verdadera tuición que se propuso el legislador del Código Civil al refrendar un nuevo de legítima en sus normas. Se trata, como dice el propio Tribunal, la que él ofrece -y no la que quiere imponer el recurrente-, una interpretación de la norma legal acorde con las vicisitudes de la vida. 
EN LA BÚSQUEDA DE UN ROSTRO PARA EL BOCETO DEL LEGISLADOR: LA CONDICIÓN DE “HEREDERO” ESPECIAMENTE PROTEGIDO (LEGITIMARIO ASISTENCIAL) EN LA INTERPRETACIÓN DEL TRIBUNAL

Supremo DE CUBA

\section{El ReCONOCIMIENTO POR EL TESTADOR DE LA CONDICIÓN DE LEGITIMARIO aSisTENCIAL A QUIEN EN DERECHO NO CORRESPONDE}

No menos trascendente ha sido el supuesto fallado por el Tribunal Supremo en que el testador en su testamento ha reconocido como especialmente protegida a una menor que en realidad no era pariente de él, dentro de los que el Código Civil le atribuye la condición de legitimarios (dígase ascendientes, descendientes), así como también al cónyuge.

En este sentido cabría preguntarse: ¿Hay error en la manifestación de voluntad testamentaria en la que su autor reconoce a una niña a la que le profesa extremo cariño, la condición de especialmente protegido sin serla? ¿ Se trata de un error en la cualidad de las personas? ¿Trasciende en la eficacia del acto testamentario?

El testador había otorgado testamento ante notario el 24 de febrero de 2003, en cuya cláusula segunda reconoce a una menor como su hija, sin serlo y le atribuye la condición de heredera especialmente protegida. En la tercera de las cláusulas del mencionado testamento, aun otorgándole el erróneo carácter de especialmente protegida, la instituye heredera en la mitad de sus bienes conjuntamente con sus tres hijos y la señora $\mathrm{X}$, y le lega, de forma inequívoca en la propia cláusula, su cuenta bancaria de por mitad con la mencionada señora X. Ante tales hechos, uno de los hijos del testador ejercita la acción de nulidad parcial del testamento, sobre la base de la existencia de error en la manifestación de voluntad del testador por reconocer como especialmente protegida a alguien que sabía el propio testador que no era su hija y, en consecuencia, es obvio que no cumple el primer requisito que establece el artículo 493.1 del Código Civil. El tribunal a quo declara con lugar la demanda interpuesta, sentencia contra la cual se interpone recurso de casación.

De dicho recurso de casación conoce la Sala de lo Civil y de lo Administrativo del Tribunal Supremo, quien a través de su Sentencia No 898, de 29 de diciembre de 2006 (ponente Díaz Tenreiro), lo declara con lugar. A juicio del Tribunal de Casación no se aprecia error en la institución de heredero, a cuyo tenor se le atribuye indebidamente la cualidad de especialmente protegida a la menor, si bien no niega que existe un error material que no trasciende jurídicamente, pues de la lectura de las cláusulas testamentarias es fácilmente apreciable el interés del testador por beneficiar a la menor, aún más allá de la condición de especialmente protegida putativa con la que la abriga. ¿¿Realmente incurrió en error el testador? A mi juicio, error como apreciación equivocada de la realidad que distorsiona el sentido mismo de la manifestación negocial de voluntad (en el caso testamentaria), y que además haya incidido notablemente en el otorgamiento del testamento, no existe. Ni tan siquiera, un error en la cualidad de las personas, reconocido en el artículo 70 c) in fine del Código Civil. No se ve afectado el animus testandi. Quedó evidentemente probado que el testador quería beneficiar a la menor, y que incluso en la manera en que lo hizo ni tan siquiera se autolimitó el ius disponendi por causa de muerte en razón de la existencia de legitimarios. Tampoco pudo probarse que con la distribución que hizo 
de su caudal afectó al resto de sus hijos, a los cuales instituyó también herederos. No obstante, sí que hay una declaración errónea en sentido lato por parte del testador al atribuirle una condición de la que no era atributaria la menor ${ }^{30}$, tildado ello por el Alto Foro como “inexactitud” en el primer Considerando de la sentencia de casación, y luego, "declaración (...) errónea" en el único Considerando de la segunda sentencia. A criterio del propio Tribunal se trata, respecto del testador, de "(...) una manifestación ociosa de motivación afectiva, que no invalida su voluntad, habida cuenta que ésta quedó plasmada claramente en la tercera de las cláusulas del documento notarial, en la que aun otorgándole el erróneo carácter de especialmente protegida, la instituye heredera en la mitad de sus bienes conjuntamente con sus tres hijos y la señora $(\mathrm{X})$, y le lega, de forma inequívoca en la propia cláusula su cuenta bancaria, de por mitad con la mencionada (señora X), pronunciamiento que constituye el núcleo esencial del testamento y que no deja lugar a dudas en cuanto a su voluntad". Ahora bien, ¿qué entender por "manifestación ociosa de motivación afectiva”? ¿En qué sentido el Alto Foro encuentra la ociosidad de la manifestación de voluntad externada por el testador? En un ejercicio de pura aproximación hermenéutica, la manifestación de voluntad testamentaria en la cual su autor reconoce a una persona como especialmente protegida, cuando en realidad no lo es, pero a la vez si con ello no restringe su libertad de testar en tanto no tiene otros herederos especialmente protegidos y le atribuye una participación igual a la del

\footnotetext{
${ }^{30}$ También lo hay del notario que como profesional del Derecho debió advertir al menos, que se estaba reconociendo como especialmente protegida en un testamento a una menor que no llevaba como primer apellido el primero del testador, tratándose de una descendiente de un varón, era ineludible que así fuera, motivo por el cual debía coincidir el primer apellido de la hija con el del padre (vid. artículo 45 de la Ley del Registro del Estado Civil).

En mi experiencia como notario también conocí del caso en que la testadora en su testamento reconoció como "heredero" especialmente protegido a su hermano, judicialmente incapacitado, por quien tenía especial desvelo y atención. Es lógico que la notaria no podía haber autorizado el testamento en los términos en que redactó esa cláusula, pues al amparo del artículo 493.1 del Código Civil, la condición de especialmente protegido no se extiende a los hermanos, así de sencillo. Fue suficiente comprobar tal extremo para no tenerlo como legitimario, a los efectos de ejecutar el testamento a favor del heredero voluntario. La cláusula en cuestión de la escritura de adjudicación de la herencia de la finada señora a favor del heredero voluntario quedó redactada de la siguiente manera:

"CUARTA: Que en el mencionado testamento, la testadora, declaró en la primera de sus cláusulas que tenía un heredero especialmente protegido, nombrado este A. D. P., hermano de la hoy causante, por lo cual, acreditado en este acto que el vinculo parental existente entre la testadora y el hipotético heredero especialmente protegido no está comprendido dentro de los que el Código Civil establece en su artículo 493.1 para estar favorecido de la condición de legitimario, es inoperante el contenido de dicha cláusula, al no resultar limitada la facultad de disposición por causa de muerte de la testadora, ni al momento de testar, ni tampoco al momento del fallecimiento, época, esta última, en la que deben cumplimentarse los requisitos exigidos ex lege para arroparse de la cualidad de legitimario, motivo por el cual se entiende que la testadora siempre tuvo libre facultad dispositiva mortis causa. En tal sentido, doy fe en este acto que he tenido a la vista y he adjuntado a la matriz para que formen parte del protocolo a mi cargo, las certificaciones de nacimiento de los hermanos S. y A., de apellidos D. P., expedidas el 12 de junio de 2008 y el 13 de noviembre de 2009, ambas por la registradora a cargo del Registro del Estado Civil de Playa, en esta ciudad, en las que se acredita que el nacimiento de la primera obra asentado en el tomo (...), folio (...), y el del segundo en el tomo (...), folio (...), ambos del Registro del Estado Civil del municipio Cienfuegos, provincia homónima".
} 
EN LA BÚSQUEDA DE UN ROSTRO PARA EL BOCETO DEL LEGISLADOR: LA CONDICIÓN DE “HEREDERO” ESPECIAMENTE PROTEGIDO (LEGITIMARIO ASISTENCIAL) EN LA INTERPRETACIÓN DEL TRIBUNAL

resto de los herederos nombrados (hijos y cónyuge), resulta algo perezoso, inocuo, que en nada transgrede los principios informantes del Derecho sucesorio. El apelativo afectivo, viene de la razón que motiva el tratamiento de especialmente protegido putativo, de la que resulta favorecida la menor que en el orden de los afectos, al parecer ocupaba un lugar señero en el corazón del testador. En todo caso, no trasciende en el ámbito jurídico, a pesar de la alarma desatada. Ello es remarcado por el juzgador en el segundo Considerando de la primera sentencia o sentencia de casación objeto de examen, de modo que la inexactitud en la que incurre el testador, no “... afecte la validez del acto ni del documento, ni mucho menos contravenga una prohibición legal al punto de la nulidad, pues si bien la menor no se encuentra comprendida en el acápite primero del artículo cuatrocientos noventa y tres del Código Civil, también lo es que la declaración de ese carácter por parte del testador no estuvo aparejada de los derechos que el heredero especialmente protegido goza en el artículo siguiente, pues su mención fue solo referativa, y el propio causante se desentiende de ella y dispone de sus bienes a su antojo, resultando inobjetable que en el testamento, cuya nulidad se pretende, queda suficientemente claro y determinante la declaración de herederos formulada por el causante, aun cuando a esta le apellide el inexistente término de 'especialmente protegido', y el destino a seguir por sus bienes". Particular que luego refuerza en el único Considerando de la segunda sentencia, al aducir: “. . la declaración de hija y heredera especialmente protegida a favor de la menor (...), si bien errónea, no afecta la declaración de voluntad del testador, manteniéndose por ende intacto el acto jurídico que la contiene, habida cuenta que se demostró que su declaración tuvo un contenido de origen afectivo, con el fin de proteger a la menor que convivía con él y a quien le prodigaba el cariño de un padre, de tal suerte que subsiste su declaración, al disponer de sus bienes con la libertad que la ley le confiere, de forma que no existe lugar a dudas, de abi que el Testamento que pretende anularse no contiene vicios que permitan alegar que es ineficaz, al no encuadrarse en el inciso ch) del artículo sesenta y siete del Código Civil en relación con el cuatro y cuarenta y nueve del propio cuerpo legal (...)". Ahora bien, la intrascendencia del equívoco del testador, hace que no zozobre la institución de heredero testamentario, porque el testador en el propio testamento, ante la ausencia de otro especialmente protegido, distribuye el caudal a su antojo, con especial merecimiento para la menor, aun cuando ésta no hubiese sido legitimaria. Su condición de legitimaria putativa en nada le beneficia, pero si con ello hubiere perjudicado la libertad de testar del testador, sí que hubiera motivado el ejercicio de la acción de nulidad sobre la base de una formación equívoca de la voluntad testamentaria.

\section{El control notarial o judicial eX POST Del CUMPLimiento de la CONDICIÓN DE ESPECIALMENTE PROTEGIDO AL MOMENTO DEL \\ DECESO DEL TESTADOR}

Precisamente en razón de lo que he venido explicando que los condicionantes o requerimientos legales para cobijarse en la condición de especialmente protegido 
en sede de legítimas han de cumplimentarse al momento del deceso del testador, compete al notario o al tribunal su control.

El notario tiene el deber de controlar el cumplimiento de los requisitos de la especial protección al momento del deceso del testador. No se trata de un acto que compete a la autonomía de la voluntad de los herederos. No puede olvidarse que la legítima comprime la parte de libre disposición, si no se tienen legitimarios, la libre disposición es el total del patrimonio hereditario del causante. Cuando éste les reconoce y les atribuye esa mitad lo está haciendo por respeto a la ley que le impone el deber de legítima, por ello lo atinado es que el testador diga en su testamento, que en la parte de libre disposición que tenga o que tuviere al momento de su deceso instituye y nombra como herederos universales o como legatarios a las personas que él desee, o en todo caso, que exprese que en el todo de la herencia nombra como herederos a dichas personas, de modo que si al momento de su muerte no hay legitimarios, el todo le corresponde a sus herederos voluntarios, que pueden coincidir perfectamente con los legitimarios que reconoció, de la misma manera que si no reconoció legitimarios, pero los instituyó herederos universales en el todo, no habría preterición, pues los tuvo en cuenta y le atribuyó bienes del acervo hereditario. Otra cosa sería, y es posible que suceda, que no les reconozca como especialmente protegidos y sí como herederos universales, pero al ser varios, $v$. gr., en el caso de sus descendientes, los instituya en partes iguales, y por regla matemática a los que son legitimarios (minoría) les corresponde en total menos de la mitad, supuesto en el cual las propias matemáticas harían que los legitimarios afectados pudieran ejercitar la acción de complemento de legítima, bajo la cobija del artículo 494 del Código Civil, pero nunca la acción de nulidad de la institución de heredero ex artículo 495.1 del Código Civil, aun y cuando en el testamento no se haya hecho mención alguna de su cualidad de "herederos" especialmente protegidos, pues no habría preterición material, incluso ni formal, pues los tuvo en cuenta aunque no les hubiere nombrado como correspondía en Derecho ${ }^{31}$.

Existe, no obstante, la práctica notarial de atribuirles la mitad de la herencia al especialmente protegido y la otra mitad de libre disposición a los herederos voluntarios. En tal caso ¿qué acontecería si al momento del deceso del testador, ya los legitimarios reconocidos no son tales? Una interpretación del testamento pudiera afectar los derechos de los herederos universales a los que le fueron atribuidos la "mitad" de libre disposición, pues en ese momento, trascendental en sede sucesoria, no hay mitad de libre disposición, sino el todo, al no subsistir la legítima que frenaba la libre voluntad del testador. Una interpretación correctora del testamento permitiría su adecuada ejecución, entendiendo que el testador se refería a lo que resultare de libre disposición a su deceso, ya fuera una mitad o el entero. Situación más difícil operaría cuando la partición se hace en el propio testamento, de modo

\footnotetext{
${ }^{31}$ Vid. per omnia en el Derecho cubano, Alfaro Guillén (2012), passim.
} 
EN LA BÚSQUEDA DE UN ROSTRO PARA EL BOCETO DEL LEGISLADOR: LA CONDICIÓN DE “HEREDERO” ESPECIAMENTE PROTEGIDO (LEGITIMARIO ASISTENCIAL) EN LA INTERPRETACIÓN DEL TRIBUNAL

que el testador deja esclarecido qué bienes serían atribuidos al legitimario y qué bienes a los herederos voluntarios, ya que de no existir legitimarios a su deceso, en principio, dichos bienes no acrecerían a los herederos voluntarios, pues la legítima y la libre disposición son partes determinadas del caudal hereditario que hace a sus beneficiarios dueños de un cuerpo cierto y determinado de bienes, presupuesto que haría inoperante las normas sobre acrecimiento hereditario (vid. artículo 471 del Código Civil). Tendría entonces que abrirse la sucesión ab intestato, lo cual no necesariamente era la voluntad del testador, más bien diría que era lo contrario. Aquí juega un papel esencial la labor de asesoramiento del notario, dado que la gran mayoría de los testamentos que se otorgan en Cuba son notariales, no ológrafos ni especiales. Es el notario quien tiene que moldear esa declaración postrera de voluntad que constituye el testamento. Nadie mejor que él para conocer agudamente las sucesiones mortis causa y redactar con pulcritud las cláusulas testamentarias. Como aduce Vallet de Goytisolo: "El notario puede intervenir en el actum, como asesor, como traductor jurídico de la voluntad empírica de los otorgantes y siempre es función suya la de redactor del dictum"32. De ahí que compete a él no sólo traducir al lenguaje jurídico la voluntad del testador, sino también la de redactar en el instrumento esta voluntad con la mayor exactitud posible, conforme con los designios que ella exige.

En cualquier circunstancia, el control del cumplimiento de los requisitos de la especial protección es deber inexcusable del notario o del tribunal. No es posible que los herederos pacten sobre ello. Se trata de normas de ius cogens, el legitimario tiene derecho a la legítima no porque el testador quiere, sino porque al testador se lo impone el legislador. Si usted quiere que su hijo sea el heredero de todo su patrimonio y su hijo tiene 5 años de edad, además de reconocerle su condición de legitimario y atribuirle la legítima, debe nombrarlo como heredero universal en el todo de la herencia, de manera alternativa, subsidiaria y previsora. Alternativa, porque usted está previendo que a su deceso ya su hijo no sea legitimario; subsidiaria, porque esta disposición está en correspondencia con su libérrima voluntad, con el Derecho dispositivo que, en materia de legítimas cede ante las normas imperativas que protegen los derechos de los destinatarios de ésta, y previsora porque como todo el contenido del testamento, el testador tiene que prever las circunstancias reinantes al momento de su deceso que pueden ser muy distintas a las existentes en el instante en que otorga el testamento.

Si como ha dicho el Tribunal Supremo a través de su Sala de lo Civil y de lo Administrativo, las normas sobre legítimas tienen un carácter excepcional en nuestro Derecho positivo, posición con la que estoy conteste ${ }^{33}$, no puede admitirse ni

\footnotetext{
${ }^{32}$ Vallet de Goytisolo, Juan B. (2006). "Determinación notarial del Derecho”. En: Derecho Notarial, T. I, Pérez Gallardo, Leonardo B. y Lora-Tamayo Rodríguez, Isidoro (Coords.), La Habana: Félix Varela, p. 102.

${ }^{33}$ Vid. supra 2.2.1.
} 
en sede notarial, ni en sede judicial, que un sujeto reconocido como legitimario en testamento, pero que no cumple los requerimientos de ley al momento de la muerte de éste, se adjudique una herencia a la que no tiene derecho. Sencillamente carece de derecho subjetivo, porque perdió la cualidad de legitimario. Él no estaba reconocido como legitimario por entera voluntad del testador, sino porque el legislador le impone al testador el cumplimiento del deber de legítima, so pena que se desate el espectro de sus acciones protectoras tanto en el orden cuantitativo como en el orden cualitativo, con los efectos fatales que pudiera tener para la subsistencia de las cláusulas de contenido patrimonial el éxito de la acción reconocida en el artículo 495.1 del Código Civil.

El freno a la libertad de testar en nuestro ordenamiento jurídico no es regla, sino excepción. Si usted no tiene los legitimarios asistenciales a que alude el artículo 493.1 del Código Civil, usted puede testar libremente sobre el todo de su patrimonio, pero entiéndase que esta regla hay que interpretarla y aplicarla conforme con el momento del deceso del testador, no sólo con el del otorgamiento. $\mathrm{Si}$ al otorgar el testamento no fue previsor y sobrevino un especialmente protegido que no lo era en el momento del otorgamiento del testamento, hay preterición formal y material y al haber preterición, tendría éxito la acción de nulidad de la institución de heredero, pero si al otorgar el testamento había un especialmente protegido, pero ya no lo era al momento del deceso del testador ${ }^{34}$, cae la barrera que obstaculizaba la libre disponibilidad del patrimonio por causa de muerte, y el heredero voluntario tiene derecho a adjudicarse el todo del caudal hereditario porque esa fue la voluntad del testador cuando dispuso que su heredero voluntario, lo fuera, $v$ gr., su hija y no su hijo. No obstante, siempre me temo que por desconocimiento de nuestro sistema legitimario, lo cual, repito, es inexplicable, el notario no le haga esa advertencia al testador, pues puede darse el caso que el testador sí quisiese que ambos hijos le heredaren, pero como uno era menor de edad, resolvemos con "equidad" la distribución del caudal patrimonial, atribuyéndole al legitimario la legítima que le compete (equivalente a la mitad) y a la heredera voluntaria la otra mitad. Posición que lacera y vulnera los derechos del testador, pues ni el hijo tendrá derecho perennemente a esa mitad, si no cumple con todos los requisitos legales que impone el legislador para erigirse en legitimario asistencial, ni la verdadera voluntad del causante fue ésa, sino que en todo caso su hijo también heredase, por lo tanto, lo atinado hubiera sido expresar en el testamento que de no reunir a su fallecimiento el legitimario los requisitos establecidos en la ley para arroparse de tal cualidad, le instituye y nombra al igual que a su hija y a partes iguales en lo que resultare de libre disposición a su deceso, o (otra fórmula testamentaria) en el todo de la herencia.

\footnotetext{
${ }^{34}$ Vid. el caso fallado por el Tribunal Supremo que motivó mis comentarios, Pérez Gallardo (2011b).
} 
EN LA BÚSQUEDA DE UN ROSTRO PARA EL BOCETO DEL LEGISLADOR: LA CONDICIÓN DE “HEREDERO” ESPECIAMENTE PROTEGIDO (LEGITIMARIO ASISTENCIAL) EN LA INTERPRETACIÓN DEL TRIBUNAL

Insisto, no le es dable al notario autorizar una escritura de partición y adjudicación de herencia en que concurra un legitimario putativo, o sea, quien realmente no lo es por no reunir los requisitos legales al momento del deceso del testador, aun cuando haya pleno "acuerdo" entre los coherederos concurrentes, pues los herederos voluntarios no pueden contravenir las normas de ius cogens que regulan la legítima asistencial en nuestro ordenamiento jurídico. Si no se es legitimario, se carece de derecho subjetivo para reclamar la legítima, es como si los herederos de común acuerdo hicieran concurrir a la partición a una persona vinculada afectivamente con el testador, pero no instituida por éste como heredero o legatario de parte alícuota. Recuérdese que el legitimario sólo es reconocido por el testador, su configuración es legal, no voluntaria. El legitimario se aproxima así al heredero ab intestato.

¿Cómo puede operar el control notarial?

Pues se necesitará probar ante notario que el legitimario no reúne los requisitos de ley. Se necesitará la práctica de prueba testifical o documental. Por ello, sería recomendable la autorización, previa a la escritura de partición y adjudicación hereditaria, de un acta de notoriedad que pruebe que el fallecido testador no tenía a su deceso "heredero" especialmente protegido alguno, en tanto él o los que fueron reconocidos en el testamento no reunían los requerimientos legales. Quizás fuera conveniente una certificación salarial del pretenso legitimario, una certificación de nacimiento para probar que ya había arribado a la mayoría de edad, o la práctica de una prueba testifical para probar el hecho negativo de que el pariente o cónyuge tenía plena aptitud para trabajar y por su libérrima voluntad no se había incorporado ${ }^{35}$. Recordemos que el artículo 85 e) del Reglamento de la Ley Notarial regula las actas de notoriedad como aquellas que “... acreditan la comprobación o fijación de hechos notorios sobre los cuales podrán ser fundados, declarados o reconocidos derechos o se legitimen hechos, situaciones o circunstancias personales o patrimoniales, con trascendencia jurídica". Se trata de declarar la notoriedad del fallecimiento del testador sin legitimario como vía para hacer valer los derechos que le competen a los herederos voluntarios sobre el todo de la herencia sobre el cual pendía la legítima, a la postre inexistente. En tanto que el artículo 103 b) del propio Reglamento,

\footnotetext{
${ }^{35}$ Aunque dirigido su análisis a la práctica de la prueba testifical en sede acta de notoriedad en función de declaración de herederos ab intestato, CHIKOC BARREDA apunta que "en ella el hecho principal a acreditar: la notoriedad, no es un elemento sensible o perceptible por la experiencia directa del Notario, sino por la declaración de aquellos que tienen con los hechos una relación concreta y que, en consecuencia, pueden asegurar su realidad de ciencia propia", y en el mismo sentido agrega: "La esencialidad de la prueba testifical, queda, por tanto, justificada. El Notario no funciona en las actas de notoriedad, como el testigo cualificado, con rol protagónico e independiente que señala la dogmática en materia de actas notariales. Existe, recordemos, esa desviación de la función notarial típica (...), en la cual la declaración de la situación jurídica, dependiente de la valoración sobre la suficiencia del material probatorio, confiere al Notario una facultad decisoria ajena al contenido esencial de la fe pública". Vid. ChiKoc BARreda, Naiví (2007). La actuación notarial en las actas de declaratoria de herederos. Tesis en opción al título de especialista en Derecho Notarial, Facultad de Derecho, Universidad de La Habana, bajo mi dirección, inédita, p. 129.
} 
en ocasión de regular este tipo instrumental de acta notarial, deja explícito que "el Notario practicará o exigirá cuantas pruebas estime necesarias para comprobar la notoriedad pretendida”. Sólo, tras la práctica de las pruebas pertinentes, podrá el notario dar el juicio de notoriedad requerido ${ }^{36}$.

También se han dado casos en que el sujeto que no cumple con los requisitos para ser legitimario es el propio promovente del instrumento notarial. No se trata de una renuncia. Recordemos que renuncia el legitimario ${ }^{37}$. Pudiera en tal supuesto el notario autorizar un acta de manifestaciones de parte, en la que la persona que había sido reconocida por el testador como legitimario y que al deceso de aquél no cumple con todos los requisitos legales, manifieste este particular ante notario competente, aportando a tal fin las pruebas que acreditan que, en efecto, o bien no dependía económicamente del causante (para lo cual adjunta documento acreditativo de su salario al momento del fallecimiento del testador) o tenía plena aptitud para trabajar (por ser mayor de edad, y en tal sentido lo acredita con la certificación de nacimiento o documento expedido por la Dirección de Seguridad Social, justificativo del cese de la pensión que por este concepto recibía al haberse incorporado al trabajo socialmente útil o a la empresa privada -dígase como trabajador por cuenta propia-).

\subsection{La dubitable declaración judicial de nulidad de la atribución por el testador de la legitima asistencial, a quien a su fallecimiento no cumpliere alguno de los presupuestos para ser atributario de ella}

Muy vinculado con los anteriores razonamientos, conviene esclarecer que el no cumplimiento de los requisitos de la especial protección exigidos por el legislador del Código Civil cubano, no implica en modo alguno la nulidad de la cláusula de reconocimiento de la especial protección de la persona o personas nombradas por el testador. Pudiera acontecer que quien nombrado especialmente protegido por el testador al momento de otorgar testamento, no lo sea, al preciso momento del deceso del testador y no por ello es dable anular tal reconocimiento.

No se trata de anular o no esa cláusula testamentaria. Un endeble análisis del artículo 67 me daría la razón ¿̇A amparo de qué apartado de dicho precepto legal se sustentaría tal nulidad? No se olvide que la acción de nulidad es de naturaleza excepcional. Los actos por naturaleza son válidos, no ineficaces (téngase en cuenta

\footnotetext{
${ }^{36}$ Como acertadamente apunta ChiKOC BARREDA “... el contenido del Acta de Notoriedad es complejo y está integrado por actuaciones del fedatario consistentes en acumular y valorar una serie de pruebas, de carácter documental y testimonial fundamentalmente, sobre determinados hechos que no le constan de ciencia propia, y que van dirigidas tanto a acreditar su realidad como su publicidad o notoriedad en el círculo limitado de personas a las cuales afecta, siendo el resultado final exteriorizar un juicio de valor por el Notario que incluso puede ser seguido de la declaración de derechos, lo que dota a esta acta de mayor grado de complejidad y especialidad en relación con otras". Vid. ChiKoc BARREDA (2007), p. 36.

${ }^{37}$ Vid. supra 2.2.5.
} 
EN LA BÚSQUEDA DE UN ROSTRO PARA EL BOCETO DEL LEGISLADOR: LA CONDICIÓN DE “HEREDERO” ESPECIAMENTE PROTEGIDO (LEGITIMARIO ASISTENCIAL) EN LA INTERPRETACIÓN DEL TRIBUNAL

que la nulidad es un supuesto de ineficacia del acto jurídico), ergo, el no cumplimiento de los requisitos de la especial protección, no conlleva a la nulidad. En todo caso, sería inejecutable esa cláusula, en tanto la previsión del testador tendrá lugar en otro sentido, o sea, en la alternativa de que de no tener herederos especialmente protegidos, el todo de su patrimonio, que se hace coincidir con la parte de libre disposición, tendrá como destinatarias las personas previstas por él mismo para el supuesto de que a su muerte, de no haber reunido aquéllas, existentes al momento de otorgar el testamento, los requisitos para ser legitimarias, yo no lo hubieran cumplido, o incluso, si se demostrara que al momento de testar, la persona reconocida por el testador en su testamento como legitimaria o especialmente protegida, no cumplía con los requerimientos impuestos ex lege, se trataría de una valoración inadecuada por parte del testador quien consideró a una persona como especialmente protegida, cuando en el orden de los hechos no lo era. No se puede olvidar tampoco que los presupuestos de no aptitud para trabajar y dependencia económica son de valoración o apreciación notarial o judicial, según corresponda, y no de mero capricho del testador. Por muy especialmente protegida que resulte una persona, a juicio del testador, si a posteriori, se prueba que no lo era, no tendrá derecho a la legítima. No obstante, algo tan sencillo como esto es resuelto por el testador, cuando al testar, de no tener -objetivamente hablando- especialmente protegidos, puede hacerlo a favor de quien quiera, para lo cual no habría que acudir a la complicada figura de los especialmente protegidos para atribuirle una mera mitad de su patrimonio, cuando a su favor tiene la libre disponibilidad de éste para quien quiera, sin ninguna otra cortapisa legal.

La litis, una vez fallecido el testador, se traba en torno a si las personas o la persona reconocida(s) por el testador como especialmente protegida(s) cumple(n) con los requerimientos legales para serlo. Quien esté interesado en lo contrario debería sustentar como pretensión la atribución in integrum del caudal hereditario, por no existir legitimario, ya sea, porque nunca hubo la convergencia de los requerimientos legales del artículo 493.1 del Código Civil en la persona nombrada por el testador como especialmente protegida en su testamento, o porque habiendo cumplido con tales requerimientos al momento de testar, esto no se prolongó hasta el momento del deceso del testador, preciso instante que ha de tenerse en cuenta para ser arropado con la condición de legitimario.

En este orden discrepo de la solución dada por la Sala de lo Civil y de lo Administrativo del Tribunal Supremo en su Sentencia No 475, de 4 de noviembre de 2011, de la que fue ponente Arredondo Suárez, que en su Considerando único de la primera sentencia, acoge el motivo primero del recurso de casación interpuesto por la parte recurrente en el sentido de apoyar la errada tesis de éste, a cuyo tenor al no demostrarse que la nombrada especialmente protegida por el testador no dependía económicamente de él (nuevamente con el argumento de la pensión ordinaria por edad a cargo de la seguridad social), anula la sentencia del tribunal de instancia y en su lugar dicta una segunda sentencia en la que en el fallamos aduce declarar "con 
lugar la presente demanda, en consecuencia se anula parcialmente el testamento notarial contenido en la Escritura Pública (...) otorgada el (...) por el causante (...), ante (...), Notaria (...), dejando sin efecto la designación de (...) como heredera especialmente protegida", o sea, acoge la tesis de la nulidad parcial del testamento por no reunir la condición de especialmente protegida la viuda del causante de la sucesión ya que al fallecimiento de su consorte gozaba de una pensión ordinaria por jubilación, sin que en efecto el tribunal se limite a controlar ex post el cumplimiento de los requisitos de la especial protección, que nada tiene que ver con la nulidad parcial del testamento, pues al resto de los herederos concurrentes, o a los propios herederos legales, de no existir éstos, le es suficiente con probar el no cumplimiento de tales requisitos legales al momento del deceso del testador para dejar sin efectos el nombramiento hecho, sin que corresponda el ejercicio de la acción de nulidad como erradamente pretendió la parte actora del proceso, luego recurrente en casación, a quien indebidamente le dio la razón el Tribunal Supremo.

\section{Post SCRIPTUM: Aún QUedAn CONTORNOS POR DEFINIR}

Reconozco que aún quedan contornos por definir del rostro de los herederos especialmente protegidos. Por muchos trazos que se hayan hecho en sede judicial, los perfiles de la figura no resultan del todo nítidos. Es cierto que la labor de los jueces ha sido decisiva en la interpretación de las escamoteadas normas que el legislador les dedica. Gracias a ella se ha ido completando el contenido de esta figura, pero no es suficiente, quedan incógnitas por despejar. La vida es mucho más rica que lo que encapsula el Derecho en normas legales, con mandatos imperativos. Los casos judiciales son diferentes, como disímiles han sido las respuestas que ha dado el Tribunal Supremo en sus sentencias, en ocasiones incluso contra todo razonamiento lógico. Aun así, no podemos negar que en el quehacer de los jueces y de los notarios, con el esfuerzo común de otros operadores del Derecho y en especial de la doctrina científica ha estado la clave para develar el verdadero rostro de los "herederos" especialmente protegidos, los nuevos legitimarios asistenciales con los que dotó al Derecho de Sucesiones el Código Civil cubano que este año cumple sus primeros veinticinco años de vida. 
EN LA BÚSQUEDA DE UN ROSTRO PARA EL BOCETO DEL LEGISLADOR: LA CONDICIÓN DE “HEREDERO” ESPECIAMENTE PROTEGIDO (LEGITIMARIO ASISTENCIAL) EN LA INTERPRETACIÓN DEL TRIBUNAL

\section{BiBLIOGRAFÍA CITADA}

Alfaro Guillén, Yanet (2012). El régimen jurídico de la preterición en Cuba. Facultad de Derecho, Universidad de La Habana.

Alpízar Rojas, María del Pilar (2010). Análisis del artículo 595 del Código Civil de Costa Rica a la luz de la jurisprudencia costarricense: ¿Una verdadera limitación a la libertad de testar? Tesis de grado, Universidad de Costa Rica, Facultad de Derecho, sede de Occidente. Disponible en: <www.iij.ucr.ac.cr/download/file/ fid/425> [consulta: 1 agosto 2012].

AA.VV. (1985). Derecho Civil soviético. T. II (traducido del ruso), Moscú: Yneshtorgizdat.

Calatayud Sierra, Adolfo (1995). "Consideraciones acerca de la libertad de testar". En: Academia Sevillana del Notariado, T. IX, Edersa.

CHIKOC BARREDA, Naiví (2007). La actuación notarial en las actas de declaratoria de herederos. Tesis en opción al título de especialista en Derecho Notarial, Facultad de Derecho, Universidad de La Habana, inédita.

Czachorski, Witold y Stelmachowski, Andrezj. "Evolución del Derecho Civil en los países socialistas". Disponible en: <http://biblio.juridicas.unam.mx/ libros/2/889/3.pdf> [consulta: 2 agosto 2012].

De la Esperanza Rodríguez, Pablo (2002). "Perspectiva de la legítima. Notas para una posible revisión”. En: Libro Homenaje a Ildefonso Sánchez Mera, Vol. I, Consejo General del Notariado.

Delgado Echevarría, Jesús (2009). “QQué reformas cabe esperar del Derecho de sucesiones del Código Civil? (Un ejercicio de prospectiva)". Disponible en: <http://www.codigo-civil.info/nulidad/lodel/docannexe.php?id=742> [consulta: 6 agosto 2012].

Fernández Martell, José Karel y Panadero de la Cruz, Ediltrudis (2011). "Las donaciones colacionables: El enigma de una institución jurídica. Incidencias sustantivas para el Derecho positivo cubano". Revista del Centro de Investigaciones Sociojurídicas de la Universidad de Caldas, Manizales, Vol. 8, No 1, enero-junio.

García Sánchez, José Aristónico (2009). "El Notario del siglo XXI”. Revista del Colegio Notarial de Madrid, No 24, marzo-abril.

Gomá Lanzón, Ignacio (2005). "Atribuciones legales (legítimas, los derechos del cónyuge viudo y de las parejas, reservas). Parte segunda. Los derechos del cónyuge viudo". En: Instituciones de Derecho Privado, Delgado de Miguel, Juan Francisco (Coord. Gral.), Garrido Melero, Martín (Coord.), T. V: Sucesiones, Vol.: $3^{\circ}$ Las atribuciones legales, Madrid: Thomson-Civitas.

IANNACCONE, Atilio (1997). "Legittimari e eredi legittimi nel diritto comparato". En: Notariato, Rassegna sistematica di diritto e tecniche contrattuali, año III, No 5, septiembre-octubre. 
LeÑa Hernández, Rafael (2000). "El tráfico jurídico negocial y el discapacitado". En: La protección jurídica de discapaces, incapaces y personas en situaciones especiales, Madrid: Editorial Civitas, $1^{\text {a }}$ Edición.

Magariños Blanco, Victorio (2005). "La libertad de testar". Revista de Derecho Privado, Nos. 9-10, septiembre-octubre. Disponible en: <http://vlex.com/vid/ libertad-testar-289842> [consulta: 7 agosto 2012].

Parra LuCÁn, María de los Ángeles (2009). "Legítimas, libertad de testar y transmisión de un patrimonio". AFDUDC, No 13. Disponible en: <http:// ruc.udc.es/dspace/bitstream/2183/7529/1/AD_13_art_24.pdf> [consulta: 6 agosto 2012].

Pérez Gallardo, Leonardo B. y Cobas Cobiella, María Elena (1999). "A una década de la promulgación el Código Civil cubano: Reflexiones sobre algunos aciertos y desaciertos de su Libro Cuarto" En: Temas de Derecho Sucesorio Cubano, La Habana: Félix Varela.

Pérez Gallardo, Leonardo B. (1999). "Los herederos especialmente protegidos, la nueva visión de los legitimarios en el Código Civil cubano: Algunas interrogantes al respecto". En: Temas de Derecho Sucesorio Cubano, La Habana: Félix Varela.

Pérez Gallardo, Leonardo B. (2000). "Naturaleza intuitu personae de los derechos deferidos a favor de los padres con especial protección (y no herederos especialmente protegidos) en el primer llamado sucesorio. (Comentarios a la Sentencia No 46 de la Sala de lo Civil y lo Administrativo del Tribunal Supremo de 29 de enero de 1999)". Revista Jurídica, Ministerio de Justicia, La Habana, No 1, enero.

Pérez Gallardo, Leonardo B. (2004a). "Constitución del derecho hereditario". En: Derecho de Sucesiones, T. I, Pérez Gallardo, Leonardo B. (Coord.), La Habana: Félix Varela.

Pérez Gallardo, Leonardo B. (2004b). "Los herederos especialmente protegidos. La legítima. Defensa de su intangibilidad cualitativa y cuantitativa". En: Derecho de Sucesiones, T. II, Pérez Gallardo, Leonardo B. (Coord.), La Habana: Félix Varela.

Pérez Gallardo, Leonardo B. (2009). "Declaración post mortem de la inoficiosidad de la donación y la protección de la legítima. (A propósito de la Sentencia No 58 de 23 de marzo de 2009 de la Sala de lo Civil y de lo Administrativo del Tribunal Supremo)". Revista Cubana de Derecho, La Habana, No 34, juliodiciembre.

Pérez Gallardo, Leonardo B. (2010a). "Algunos criterios jurisprudenciales en sede sucesoria de la Sala de lo Civil y de lo Administrativo del Tribunal Supremo. Derroteros del último lustro (2000-2004)”. En: Estudios de Jurisprudencia sucesoria, Managua: Bitecsa. 
EN LA BÚSQUEDA DE UN ROSTRO PARA EL BOCETO DEL LEGISLADOR: LA CONDICIÓN DE “HEREDERO”

Pérez Gallardo, Leonardo B. (2010b). "El Derecho de Sucesiones a la luz de la interpretación de la Sala de lo Civil y de lo Administrativo del Tribunal Supremo en el cuatrienio 2005-2008”. En: Estudios de Jurisprudencia sucesoria, Managua: Bitecsa.

Pérez Gallardo, Leonardo B. (2011a). "Legítima y discapacidad. Una relectura de los requisitos exigidos ex lege para el beneficio de la especial protección o cualidad de legitimario asistencial". Revista Norte Notarial, del Colegio de Notarios de La Libertad, Trujillo, año I, No 1.

Pérez Gallardo, Leonardo B. (2011b). "Cumplimiento de los requisitos de la especial protección (legitimario asistencial) a la muerte del testador: La situación del estudiante universitario. Comentarios a la Sentencia No 218 de 31 de mayo de 2011 de la Sala de lo Civil y de lo Administrativo del Tribunal Supremo". En: Boletín de la Organización Nacional de Bufetes Colectivos, La Habana, No 42, junio-diciembre.

Pérez Gallardo, Leonardo B. (inédito). “¿Cómo entender la dependencia económica del causante, a los fines de reclamar la legítima, en el supuesto del hijo judicialmente incapacitado, internado en centro asistencial? (A propósito de la Sentencia No 532 de 29 de diciembre de 2011 de la Sala de lo Civil y de lo Administrativo del Tribunal Supremo)".

Vaquer Aloy, Antoni (2007). "Reflexiones sobre una eventual reforma a la legítima”. InDret, 3/2007. Disponible en: <http://www.indret.com/pdf/457_es.pdf> [consulta: 6 agosto 2012].

Vallet De Goytisolo, Juan B. (2006). "Determinación notarial del Derecho". En: Derecho Notarial, T. I, Pérez Gallardo Leonardo B. y Lora-Tamayo Rodríguez, Isidoro (Coords.), La Habana: Félix Varela.

\section{NORMAS CITADAS}

Código Civil de la República de Costa Rica, 26 de abril de 1886, San José: Porvenir, 9a Edición revisada y actualizada, 1996.

Código Civil de la República de Cuba, Ley No 59/1987, 16 de julio, anotado y concordado por Leonardo B. Pérez Gallardo, La Habana: Ciencias Sociales, 2011.

Código Civil del Reino de España, 6 de octubre de 1888, Madrid: Tecnos, $24^{\mathrm{a}}$ Edición, 2005.

Código Civil de la República de El Salvador, 14 de abril de 1860, actualizado con sus reformas Ricardo MENDOZA Orantes (Ed.), Editorial Jurídica salvadoreña, 2006.

Código Civil de la República de Honduras, sancionado por Decreto No 76/1906 de 19 de enero, Tegucigalpa: Graficentro Editores.

Código Civil de la República de Nicaragua, Editorial Jurídica, 4a edición, 1999. 
Código Civil de la República de Panamá, Santa Fe de Bogotá: Mizrachi \& Pujol, 3a Edición, 1993.

Código Civil de la Federación Rusa, parte III, adoptado por la Duma, 1 de noviembre de 2001, aprobado por el Consejo de la Federación el 14 de noviembre de 2001.

Código de Familia de la República de Cuba, Ley No 1289 de 1975, Divulgación del Ministerio de Justicia, La Habana, 1999.

Ley de Seguridad Social, Reglamento, Disposiciones complementarias, 28 de agosto de 1979, Divulgación del Ministerio de Justicia, 1987. 